\title{
Assessing the sensitivity of bivalve populations to global warming using an individual-based modelling approach
}

\author{
Thomas Yoann ${ }^{1,{ }^{*}}$, Bacher Cedric ${ }^{2}$ \\ ${ }^{1}$ Laboratoire des Sciences de l'Environnement Marin (LEMAR), UMR 6539 IRD/UBO/Ifremer/CNRS; \\ 29280 Plouzané ,France \\ ${ }^{2}$ Ifremer, DYNECO, Centre Ifremer de Brest; 29280 Plouzané ,France \\ *Corresponding author : Yoann Thomas, email address : yoann.thomas@ird.fr
}

\begin{abstract}
:
Climate change exposes benthic species populations in coastal ecosystems to a combination of different stressors (e.g. warming, acidification and eutrophication), threatening the sustainability of the ecological functions they provide. Thermal stress appears to be one of the strongest drivers impacting marine ecosystems, acting across a wide range of scales, from individual metabolic performances to geographic distribution of populations. Accounting for and integrating the response of species functional traits to thermal stress is therefore a necessary step in predicting how populations will respond to the warming expected in coming decades. Here, we developed an individual-based population model using a mechanistic formulation of metabolic processes within the framework of the Dynamic Energy Budget theory. Through a large number of simulations, we assessed the sensitivity of population growth potential to thermal stress and food conditions based on a climate projection scenario (Representative Concentration Pathway; RCP8.5: no reduction of greenhouse gas emissions). We focused on three bivalve species with contrasting thermal tolerance ranges and distinct distribution ranges along $5000 \mathrm{~km}$ of coastline in the NE Atlantic: the Pacific oyster (Magallana gigas), and two mussel species: Mytilus edulis and Mytilus galloprovincialis. Our results suggest substantial and contrasting changes within species depending on local temperature and food concentration. Reproductive phenology appeared to be a core process driving the responses of the populations, and these patterns were closely related to species thermal tolerances. The non-linear relationship we found between individual life-history traits and response at the population level emphasizes the need to consider the interactions resulting from upscaling across different levels of biological organisation. These results underline the importance of a process-based understanding of benthic population response to seawater warming, which will be necessary for forward planning of resource management and strategies for conservation and adaptation to environmental changes.
\end{abstract}

Keywords : Benthic species, Dynamic Energy Budget, Population dynamics, Biogeography, Phenology, Global warming, Climate scenario 


\section{INTRODUCTION}

Marine organisms are currently experiencing an unprecedented rate of climatic warming, which affects their physiological performances (e.g. growth and reproduction), phenology (e.g. timing of ontogenic transitions) and biogeography (Philippart et al., 2003; Helmuth et al., 2006; Fly et al., 2015). Climate change is thus one of the main threats to marine ecosystem integrity, mainly due to its impact on biodiversity (Pereira et al., 2010). With respect to projected climate change by the mid21st century and beyond, global marine species redistribution and marine biodiversity change in sensitive regions will likely challenge the sustained productivity of fisheries and provision of other ecosystem services (IPCC, 2014). Understanding and foreseeing the response of populations to global change is therefore a major goal, particularly in coastal ecosystems, which are vital from ecological, social and economic points of view (Harley et al., 2006; Filgueira et al., 2016).

An important approach in the fields of population ecology, especially in the context of global changes that subject organisms to multiple stresses (e.g. warming, acidification, eutrophication, hypoxia and diseases), is to develop modelling approaches to study species distribution patterns and population dynamics (Kearney \& Porter, 2009). To this end, many studies use species distribution models (SDMs) based on spatial environmental data relevant to a given species to predict its

This article is protected by copyright. All rights reserved. 
distribution. These models may be correlative or mechanistic (Buckley et al., 2010). Correlative SDMs are based on statistical response curves between species observation data (e.g. presence, presence-absence and abundance) and environmental predictor variables (Guisan \& Zimmermann, 2000). In contrast, mechanistic SDMs are built on knowledge of the processes of response (physiological, phenological or other) to environmental variables, which will determine the demographic dynamics of species (Kearney \& Porter, 2009; Fly et al., 2015). Correlative and mechanistic approaches appear to be complementary (Mathewson et al., 2017) and each have their own limitations, mainly due to the difficulties of developing dynamic approaches with correlative SDMs and of parametrization of mechanistic models (Buckley et al., 2010). In addition, species do not all respond in the same way to global changes in terms of physiological tolerance, life-history traits, probability of extinction, colonization or dispersal (Berg et al., 2010).

Thermal stress may impair species physiological performances and survival at different stages in the life history (e.g. adult survival and reproduction efficiency, larval development timing and success or recruitment success), and lead to changes in population abundance and geographic range limits (Helmuth et al., 2006). Physiological tolerance thresholds will define the species thermal niche and will thus drive the contraction or expansion of geographic distributions (Tracy \& Christian, 1986). Comparing species physiological responses to temperature changes is a way to identify the types of lethal and sub-lethal stresses that account for observed changes in distribution patterns, and may lead to a better understanding of long-term responses at the ecosystem scale (Wethey et al., 2011; Somero, 2012). For example, Montalto et al. (2016) explored the response of three mussel species to a warming scenario in the Mediterranean Sea, through a spatially-explicit functional trait-based mechanistic modelling approach at the individual scale. They linked climate warming to life-history traits (i.e. phenological shift, increased mortality risk), and found species-specific and non-linear patterns of individual responses.

Combining biophysical ecology and metabolic theories in ecology thus forms a part of the current increase in functional trait-based modelling approaches that aim to account for multiple physiological stressors on population dynamics (Kearney \& Porter, 2009; Kearney, 2012; Fly et al., 2015; Matzelle et al., 2015). These modelling approaches give quantitative predictions of species life-history traits. In addition, the use of metabolic theories such as Dynamic Energy Budget (DEB) theory (Kooijman, 2010), offers a mechanistic and generic framework giving species metabolic responses to environmental forcing and providing a powerful tool for exploring how environmental change will likely affect physiological performances (Sarà et al., 2013; Filgueira et al., 2016; Thomas et al., 2016). This offers numerous opportunities for species or ecosystem comparison and upscaling from individual to population and community levels. Since apparently simple responses at the population level emerge from complex individual processes (Nisbet et al., 2010; Pethybridge et al., 2013), most of the current developments in the functional trait-based modelling framework have focused on individual-based modelling (IBM), to cross between individual and population scales (Martin et al., 2013). This modelling framework enables proper testing of the effect of environmental scenarios on population dynamics and demographic patterns emerging from the state of individuals. In the present paper we develop a generic spatially-explicit individual-based model. We aim to explore the response of benthic ectothermic species populations to projected seawater warming scenarios, and assess the consequences for their biogeography.

This article is protected by copyright. All rights reserved. 
The cumulative emissions of $\mathrm{CO}_{2}$ largely determine global mean surface warming and future projections of greenhouse gas emissions vary greatly depending on socio-economic development and climate policy (IPCC, 2014). Based on the possible development trajectories for the main forcing agents of climate change, climate modellers have developed a set of four representative concentration pathways (RCPs) scenarios for the end of the century, compatible with the full range emission scenarios available in the current scientific literature (van Vuuren et al., 2011). These RCPs provide a plausible and consistent description of the future, from the most stringent pathway: RCP2.6, which leads to a decline of the earth's net energy balance to $2.6 \mathrm{~W} \mathrm{~m}^{-2}$ by 2100 , to the 'business as usual' scenario RCP8.5, which leads to $8.5 \mathrm{~W} \mathrm{~m}^{-2}$ by 2100 . The Intergovernmental Panel on Climate Change (IPCC), expects that sea surface temperature will warm globally by between $1^{\circ} \mathrm{C}$ (RCP2.6) and more than $3^{\circ} \mathrm{C}$ (RCP8.5) by 2081-2100, relative to the 1986-2005 period.

In the context of these proposed scenarios, we applied our modelling approach to the coast of the Bay of Biscay and English Channel. Contrasting patterns exist between current and projected thermal conditions for this area (Holt et al., 2010) and it is considered a biogeographic boundary for many species (Jolly et al., 2004). The three benthic species selected for this study were the Pacific oyster: Magallana gigas (previously known as Crassostrea gigas), and two Mytilidae: Mytilus edulis and Mytilus galloprovincialis. These three species are widely distributed and are important ecosystem engineers in marine benthic systems (Grabowski et al., 2012). They aggregate, thus modifying the nature and complexity of benthic substrates and contribute to benthic-pelagic coupling through filtration and bio-deposition processes. Fisheries and aquaculture exploit these species on a broad scale worldwide. In the study area, these species show contrasted biogeographic patterns: Mytilus edulis is a species from cold temperate areas, distributed in the North-East Atlantic from northern Europe to the northeastern Spanish coast. Mytilus galloprovincialis is a Mediterranean species that is found up to the north of the Scottish islands. Magallana gigas was introduced to French coasts at the end of the 1960s and has since colonized all European coasts, especially under the effect of global warming, which has enabled the poleward expansion of its thermal niche (Troost, 2010; Thomas et al., 2016).

We used spatially explicit forcing variables to drive a bioenergetic model at the individual scale on the basis of Dynamic Energy Budget (DEB) theory (Kooijman, 2010). The DEB model simulates the life-history traits of each species (i.e. energy uptake, growth and reproduction) as a function of environmental variables (i.e. temperature and food). We integrated this model into an $i$-state density-independent population dynamics model with an IBM approach, in line with Pethybridge et al. (2013) and then applied the model to a number of locations selected on the basis of available information regarding the potential habitat of the species. We made the assumption of no biotic interactions (i.e. carrying capacity or spatial competition) or spatial connections (i.e. connectivity processes). We used one RCP projection for 2100 (RCP8.5) to build climate scenarios and assess how thermal stress and food limitation applied at the individual scale would affect species responses at the population scale across the studied area. Our main goals were then to analyse i) which species can be viewed as winners or losers and ii) how life history traits act on the response at the population level under well documented warming scenarios in different locations in the NE-Atlantic.

This article is protected by copyright. All rights reserved. 


\section{MATERIALS AND METHODS}

\section{DEB Bioenergetics model}

The DEB model offers a generic framework to describe the energy flow through an organism in a varying environment, from energy uptake to its use for growth, development, reproduction and maintenance (Kooijman, 2010). It covers the full life cycle of an individual (embryo, juvenile and adult) and provides quantitative information on mass and energy balances. Several applications of the DEB model have examined bivalve physiological responses to environmental changes and quantified the consequences in terms of growth, physiological condition and reproductive output (e.g. Bernard et al., 2011; Sarà et al., 2013; Thomas et al., 2016). Briefly, four state variables are simulated by the DEB model: the structural body volume $\left(V, \mathrm{~cm}^{3}\right)$; the reserve $(E, \mathrm{~J})$; the maturity level $\left(E_{H}, J\right)$, which gives the amount of energy spent in organism development and defines the transition between life stages; and the reproduction buffer $\left(E_{R}, J\right)$, which is the energy allocated to the production of gametes. The model equations are summarized in Table S1. A full description of the main properties of the DEB model can be found in Sousa et al. (2008).

Two forcing variables modulate metabolic rates and drive individual growth and reproduction in the DEB model: temperature and food density. When exposed to high concentrations of suspended particulate inorganic matter (PIM), bivalves maximize organic ingestion through pseudo-faeces production. We therefore introduced PIM concentration as a third forcing variable, related to the ingestion functional response $(f \in[0,1])$, following Kooijman's (2006) conceptualisation:

$$
f=\frac{X}{X+K\left(1+\frac{Y}{K_{Y}}\right)}
$$

where $X$ is the food density, $Y$ the PIM concentration, $K$ the half saturation coefficient related to food density and $K_{Y}$ the half saturation related to inorganic matter concentration.

In the DEB model, seawater temperature acts on metabolic rates following the Arrhenius function, extended over the species tolerance range, based on the idea that the metabolic rates are controlled by enzymes that have an inactive configuration beyond the optimal temperature range (Kooijman, 2010), and giving a temperature correction factor $\left(T_{C}\right)$ :

$$
T_{C}=\exp \left\{\frac{T_{A}}{T_{1}}-\frac{T_{A}}{T}\right\} \cdot\left(1+\exp \left\{\frac{T_{A L}}{T_{1}}-\frac{T_{A L}}{T_{L}}\right\}+\exp \left\{\frac{T_{A H}}{T_{H}}-\frac{T_{A H}}{T_{1}}\right\}\right) \cdot\left(1+\exp \left\{\frac{T_{A L}}{T}-\frac{T_{A L}}{T_{L}}\right\}+\exp \left\{\frac{T_{A H}}{T_{H}}-\frac{T_{A H}}{T}\right\}\right)^{-1}
$$

where $T$ is the actual temperature, $T_{A}$ the Arrhenius temperature in the tolerance range, $T_{1}$ the reference temperature $\left(20^{\circ} \mathrm{C}\right)$ for which $T_{C}=1, T_{L}$ and $T_{H}$ are the lower and higher boundaries of the optimal tolerance range and $T_{A L}$ and $T_{A H}$ the Arrhenius temperatures beyond the lower and higher boundaries, respectively.

Spawning events are triggered in the DEB model when two thresholds are concurrently reached: a seawater temperature threshold and a gameto-somatic index (GSI) threshold, where GSI is defined as a mass ratio between the gametes and total dry flesh mass (see values in Table S2). Since high temperatures may inhibit reproduction (Shpigel et al., 1992; Fearman \& Moltschaniwskyj, 2010), a maximum temperature threshold inhibiting spawning was added for each species (see values in Table S2). Temperatures between the lower and upper thresholds may be viewed as the spawning

This article is protected by copyright. All rights reserved. 
window. We considered spawning events as complete, the reproductive compartment $\left(E_{R}\right)$ thus being emptied when spawning occurred.

In this study, the DEB model parameters were derived from the literature for the three species $(M$. gigas: Thomas et al. (2016); M. edulis: Saraiva et al. (2012); M. galloprovincialis: Rinaldi et al. (2014)) (Table S2). For both mussel species, clearance rate measurements at various temperatures from Fly \& Hilbish (2013) were used for estimating the Arrhenius function parameter values. For M. gigas, a set of published data on respiration (R), ingestion (I) or gametogenesis (G) were used (Bernard, 1974 (R, I); Kusuky, 1977 (I); Mann, 1979 (G); Kim, 1980, 1995 (R); Le Gall \& Raillard, 1988 (R, I)); Shpigel et al., 1992 (R, G); Bougrier et al., 1995 (R, I); Ren et al., 2000 (R, I); Chavez-Villalba et al., 2002 (G); Fabioux et al., 2005 (G); Mao et al., 2006 (R); Le Moullac et al., 2007 (R, I); Lannig et al., 2010 (R)). Prior to parameter estimation, data were scaled by dividing by the averaged value found at the reference temperature $T_{r e f}=20^{\circ} \mathrm{C}$. A nonlinear regression was then performed to estimate the Arrhenius function parameters, using the nonlinear (weighted) least-squares function $n / s$ in $R(R$ Development Core Team, 2012). DEB parameters were first validated against data from published studies giving time series of environmental variables and species growth in several locations along European coasts (Fig. S1).

\section{Population dynamics model}

Following the work of Pethybridge et al. (2013), our IBM is an $i$-state configuration model in which large numbers of cohorts are followed as discrete entities. The DEB model simulates individual growth trajectories and spawning events. Every cohort (i) is treated individually as a super-individual (Scheffer et al., 1995) with the same DEB state variables and a given number of individuals $\left(N_{i}\right)$. A new cohort $(i+1)$ is potentially generated every day $(t)$ depending on the reproductive status of the $i$ cohort. The cumulative number of eggs spawned at time $t$ by all the spawning cohorts gives the initial abundance $\left(N_{i+1}\right)$ of cohort $(i+1)$. We assumed that $50 \%$ of the population correspond to females and produce eggs, corresponding to the mean proportion in natural populations (Yusa et al., 2013; Yasuoka \& Yusa, 2016). The larval phase is not taken into account and growth trajectories are considered to start after settlement. Thus, we considered that the initial number of settled individuals corresponds to the total number of eggs produced, exposed to a cumulative presettlement mortality factor $\left(M_{L}\right)$, cumulative fertilization success, egg survival and larval mortality (Thorson, 1950; Rumrill, 1990). The abundance of each cohort is then exposed to a daily mortality rate: $d N_{i} / d t=N_{i} \cdot M$ set at $15 \%$ year $^{-1}$ (Gangnery et al., 2001, 2004). The DEB model makes it possible to simulate the process of mortality associated to ageing. However, this process requires two additional parameters for each species (see Kooijman, 2010), which would increase the level of uncertainty in the overall model. Moreover, ageing does not take into account the whole range of mortality processes related to food and temperature, as Martin et al., (2013) demonstrated with their population dynamics model for daphnia. Since information on the species we studied is lacking, we decided not to include ageing in the present model. The total stock biomass trajectory can be computed as $B=\sum_{i} N_{i} \cdot W_{i}$, where $W_{i}$ is the total weight ( $\mathrm{g}$ ) of individuals in cohort $i$ extracted from the DEB simulations (see Table S1). The lifespan of an individual is set at 12 years for $M$. gigas and 10 years for M. edulis and M. galloprovincialis, which is consistent with field observations (Thompson, 1984). After that time, remaining individuals in a given cohort are removed.

This article is protected by copyright. All rights reserved. 
Each simulation is initialised with a single cohort of 50,000 post-metamorphosis individuals with a given mass, structure, reproduction and reserve value, set in every studied location. New cohorts are created after each spawning event. Since no biological interactions were included in the present model (i.e. no connectivity or competition for food or space), the population trajectories follow an exponential profile. In order to compare the climate scenarios and to describe the geographical heterogeneity in population growth rates, we computed a population growth rate (PGR) index, defined as the slope of the log-transformed (and thus linearized) total stock biomass trajectory in a selection of locations described hereafter.

\section{Habitat selection}

Our target species are known to colonize rocky shore coastal areas. To define habitats, we therefore used the EUSeaMap mapping, which is a product of the European EMODNET Seabed habitats project (http://www.emodnet.eu/seabed-habitats). This project is aiming to map benthic habitats of European waters and provides access to detailed mapping of the habitats ( $250 \mathrm{~m}$ spatial resolution), classified according to three categories: seabed substrate, biological zone and hydrodynamic energy. The choice of potential habitats for the three species of bivalves studied here was made by retaining sectors belonging to the categories "infralittoral" and "rock and other hard substrata". This method does not take into account the commercial exploitation areas on sediment (e.g. mussel reared on bouchot), since we focused on patterns of natural populations associated with geographic gradients. From all the potential habitats extracted, 150 locations were sub-sampled in order to have a robust description of environmental conditions occurring in the studied area and to minimize computational time for the population dynamics modelling.

\section{Environmental forcing}

For each location, time series of forcing variables were generated using several sources of data. Phytoplankton, described by chlorophyll-a (Chl-a, $\mu \mathrm{g} \mathrm{L}^{-1}$ ) concentration, was used as a proxy of food sources. Particulate inorganic matter (PIM) and Chl-a were extracted from satellite observations. Daily concentrations were obtained using merged data from SeaWIFS, MODIS and MERIS $\left(1 \mathrm{~km}^{2}\right.$ of spatial resolution), as described by Saulquin et al. (2011) and using a regional algorithm specifically designed for the coastal waters of the Bay of Biscay (Gohin, 2011) (http://sextant.ifremer.fr/en/). The nearest neighbour satellite pixel was chosen to represent environmental conditions in each of our 150 locations. For bivalve species, the half saturation coefficient of the functional response is known to change as a function of the food quantity and/or quality and species physiological flexibility (i.e. particle selection capacity) (Alunno-Bruscia et al., 2011). In the present study, a linear relationship between the mean $\mathrm{Chl}$-a concentration and the half saturation parameter $(K)$ was calibrated for mussel species in order to take into account feeding adaptation to local conditions. The same was done between the mean Chl-a/PIM ratio and the half saturation parameter for $M$. gigas.

For every location, time series of Sea Surface Temperature (SST) were extracted from the CNRMCM5 climate model outputs (from the French National Centre for Meteorological Research, CMIP5 archive: https://esgf-node.llnl.gov), following the nearest neighbour strategy. This model demonstrated its ability to correctly simulate the mean present-day SST seasonal cycle in the considered area with a higher ocean resolution $\left(1^{\circ} \times 1^{\circ}\right)$ and more realistic topography and coastline

This article is protected by copyright. All rights reserved. 
geometry than other climate models (L'Hévéder et al., 2017). SST from the climate model was available with a daily frequency.

\section{Scenario building}

Two climate scenarios were considered and compared in this study: one reference ("ref.") scenario with current climate conditions, based on the 2000-2015 period, and one projected ("proj.") scenario, with predicted thermal conditions at the end of the $21^{\text {st }}$ century, based on the 2085-2100 period. For the latter, we used the so-called 'business as usual' Representative Concentration Pathway scenario RCP8.5 (i.e. the rising radiative forcing pathway leading to $8.5 \mathrm{~W} \mathrm{~m}^{-2}$ by 2100), which assumes that greenhouse gas emissions continue to rise throughout the remainder of the $21^{\text {st }}$ century (van Vuuren et al., 2011). There is still a huge uncertainty on what the future will be and on the level of mitigation of the GHG emission that will be effectively accomplished. We have chosen the well documented and most severe scenario, which must be viewed as the worst scenario. We chose it to define a kind of maximum (i.e. an abacus) for responses.

Daily Chl-a and PIM concentrations were extracted from remote sensing recordings for each of the 150 locations over the 15-year period reference (2000-2015). This trophic profile was coupled with the two 15-year-period SST outputs from the climate model. This long-term environmental recording allowed us to introduce spatial and inter-annual variability and represent a set of realistic phenological scenarios (i.e. timing of the bloom compared to the seasonal thermal cycle).

In order to explore the separate effects of warming and food change on population growth rate, we tested an additional food-based scenario ("food") based on the projected Chl-a density provided by the CMIP5 archive (https://esgf-node.IInl.gov). Monthly ocean chlorophyll fields produced by the CNRM-CM5 model were thus extracted over the 2085-2100 period for every location and used to scale the satellite observation (i.e. 2000-2015 period) by applying a bias-correction method (see details in supplementary material, Fig S4).

The population dynamics model was computed over 45 -year periods. Therefore, the 15 -year forcing scenarios were used three times successively, and run with a daily time step.

\section{Model outputs}

Individual and population biological traits emerged from the individual-based population model. The DEB model produced information on individual life-history traits in every cohort, either directly or through allometric relationships: total individual length $(L, \mathrm{~cm})$ and mass $(W, \mathrm{~g})$. The IBM produced population growth rate (PGR) and statistics on reproductive traits: dates of the spawning events $\left(d_{\text {spw }}\right.$, day), fecundity $\left(F, \#\right.$ eggs ind ${ }^{-1}$ spawning event $\left.{ }^{-1}\right)$. Input data and model outputs at the 150 locations along $5000 \mathrm{~km}$ of coastline were used to compare scenarios and species.

\section{RESULTS}

\section{Spatial and temporal variability of forcing variables}

Fig. 1 gives an example of the forcing variables used in our modelling approach in two contrasting locations in the South (S1) and North (S2) of the study area (see Fig. 2 for locations). These two examples illustrate the interannual variability and seasonal patterns of all environmental variables.

This article is protected by copyright. All rights reserved. 
Averaged phytoplankton concentrations ranged from 0.6 to $5.5 \mu \mathrm{g} \mathrm{L}^{-1}$ across the 150 studied locations (Fig. 2). The greatest interannual variations in phytoplankton were shown in the northern Bay of Biscay and south-eastern and north-western English Channel (CV $\approx 20 \%$ ) (Fig. 2a). Averaged PIM concentrations ranged from 0.5 to $110 \mathrm{mg} \mathrm{L}^{-1}$ (Fig. 2b). Higher PIM levels and interannual variations were found close to the main estuaries ( $C V \approx 50-60 \%)$. Yearly mean sea surface temperature (SST, ${ }^{\circ} \mathrm{C}$ ) showed a south-north gradient going from $15.4^{\circ} \mathrm{C}$ to $10.8^{\circ} \mathrm{C}$ for the reference scenario (Fig. 2C). Interannual SST variations were small within each scenario, and followed the same geographical gradient with the largest variations simulated in the north $\left(\mathrm{CV}_{\max }=5 \%\right)$. Sea surface warming simulated by the CNRM-CM5 climate model in the 150 selected locations was of $+0.28{ }^{\circ} \mathrm{C}$ per decade on average during the 2000-2100 period, with the RCP8.5 scenario (Fig. 2d). Warming appeared stronger in the north of the studied area, along the English Channel, with close to $+0.32^{\circ} \mathrm{C}$ per decade on average, compared to the Bay of Biscay $\left(+0.28^{\circ} \mathrm{C}\right.$ per decade). Southern Brittany showed the least increase, with less than $+0.21^{\circ} \mathrm{C}$ per decade.

\section{Species temperature tolerance}

The three species exhibit distinct physiological thermal tolerances, which modulate their metabolic fluxes in the DEB model following species-specific Arrhenius response curves (Fig. 3a). Low temperature thresholds were quite similar for $M$. edulis and $M$. galloprovincialis $\left(T_{L}=4.4\right.$ and $4.9^{\circ} \mathrm{C}$, respectively), but distinct high temperature thresholds $\left(T_{H}\right)$, of $22^{\circ} \mathrm{C}$ and $27^{\circ} \mathrm{C}$, were found for $M$. edulis and $M$. galloprovincialis, respectively. $M$. gigas exhibits a high temperature threshold at $32^{\circ} \mathrm{C}$, with a large tolerance range of $29^{\circ} \mathrm{C}$ (i.e. lower threshold $T_{L}=3^{\circ} \mathrm{C}$ ) (Fig. 3a).

Taking these tolerance ranges, the consequences of the two climate scenarios were explored by computing the temperature correction factor ( $T_{C}$, see methods) from the daily values of temperature simulated in the 150 locations for the two 15-year scenarios (Fig. 3b). The $T_{C}$ probability distribution functions show three patterns depending on species: $M$. gigas exhibited a significant increase of its mean $T_{C}$ with the seawater warming scenario ( 0.66 to 0.77 ), but $T_{C \max }$ was never reached. $M$. edulis showed a slight increase of its mean $T_{C}(0.84$ to 0.89$)$, and in both reference and warming scenarios $T_{\text {cmax }}$ is exceeded. M. galloprovincialis, in contrast, had an intermediate pattern, with a more significant increase of $T_{C}$ in the warming scenario (0.65 to 0.76). Although temperatures were still in the optimal range, $T_{C_{\max }}$ appeared to be reached only with the projected warming scenario.

\section{Simulation of individual growth}

Differences in thermal tolerance between species led to different patterns in individual growth potential in the Proj. and Ref. scenarios. Yearly time series of individual growth with the two scenarios and maps of geographical growth performances with the reference scenario are given in Fig. S2 \& Fig. S3. Growth variations between climate scenarios ranged from $-1.8 \%$ for $M$. edulis close to the Gironde estuary $\left(46^{\circ} \mathrm{N}\right)$ to $+15.8 \%$ for $M$. galloprovincialis in the Eastern part of the English Channel $\left(50^{\circ} \mathrm{N}\right)$ (Fig. 4). M. galloprovincialis was the most sensitive species, with an overall average difference of $+12.6 \%$, followed by $M$. gigas with $+9.2 \%$ and $M$. edulis with $+4.0 \%$. Geographical patterns of response appeared to be species-specific and strongly related to the Arrhenius response curves. Sectors combining higher temperatures and warming, close to the Gironde estuary $\left(46^{\circ} \mathrm{N}\right)$, exhibit the most contrasting responses, with a significant increase of individual growth performance simulated for M. galloprovincialis ( $+10 \%)$, which is close to its optimal threshold; a slight increase for M. gigas (+7\%), which is under its optimal threshold; and a decrease for M. edulis $(-2 \%)$, which is

This article is protected by copyright. All rights reserved. 
beyond its optimum threshold. Only in the northern part of the studied area, close to the Irish Sea, was there an increase of individual growth performance for all three species.

\section{Response of population growth}

For each species we plotted the simulated PGR in temperature-food space, expressed in term of mean temperature conditions and mean functional response for all locations and Ref., Proj. and food scenarios combined (Fig. 5). Results can be viewed as the realized population niche with respect to food and temperature. Strong differences in PGR level are shown along the trophic gradient for the three species, highlighting the geographical variability in food conditions. Population responses across the thermal range appeared heterogeneous: a continuous increase was simulated for $M$. gigas, with high PGR reached at the upper limit, around $17^{\circ} \mathrm{C}$; higher PGR values for $M$. edulis were simulated between 13 and $15^{\circ} \mathrm{C}$, with a decrease beyond this level; and for M. galloprovincialis, PGR increased until $13^{\circ} \mathrm{C}$ then reached a plateau from 13 to $18^{\circ} \mathrm{C}$. For $M$ galloprovincialis, the food effect on PGR appears to be more important than the temperature effect: there is high growth over the entire temperature range from $12^{\circ} \mathrm{C}$ to $18^{\circ} \mathrm{C}$ when the functional response is $>0.55$. For M. edulis, growth is high at high food levels but only between $12^{\circ} \mathrm{C}$ and $15^{\circ} \mathrm{C}$. M. gigas has high growth rate only at high temperature $\left(>16^{\circ} \mathrm{C}\right)$. These results also showed the moderate effect of the expected food density variation compared to the effect of temperature when $\mathrm{Chl}-\mathrm{a}$ and temperature projections were combined in the "food" scenario: slight difference between Proj. and food scenarios results (see Fig. S5 for direct comparison). Consequently, in what follows, we focus on the effect of temperature change through the differences between model outputs with the Ref. and Proj. scenarios.

The range of simulated PGR also revealed large differences between the two climate scenarios (Fig. 6). For M. gigas, every location showed an increase of PGR, from +5 to $+626 \%$ (mean $=+73 \%$; median $=+33 \%$ ), with an increasing south to north gradient in the warming compared with the reference scenario. For $M$. edulis, $40 \%$ of the locations showed a decrease of their PGR (mean = $1.9 \%$; median $=1.4 \%$ ) between the two scenarios, with only sectors in the north of the study area showing a slight increase. For M. galloprovincialis, however, $90 \%$ of the locations showed a PGR increase (mean $=7.0 \%$; median $=6.4 \%$, with again an increasing south to north gradient.

A comprehensive understanding of the biogeographic consequences of the PGR variations is given when comparing the direction of the warming effect for the two mussel species. Locations of "winner" species, which showed an increase in their PGR in warming conditions and locations of "loser" species, which showed a decrease in their PGR, can be identified. Some areas had similar responses, with "loser-loser" (both species showed a decrease in their PGR) in northern Spain and western Brittany locations or "winner-winner" (both species showed an increase in their PGR) in Normandy and in the northernmost locations. All other areas along the Bay of Biscay and English Channel showed opposite responses, with an increase of $M$. galloprovincialis PGR and a decrease of M. edulis PGR.

Spatial patterns of population response (i.e. PGR variations) were very similar between species: Pearson correlation coefficients averaged 0.67 in pairwise comparisons (see Tables S3). The springtime seawater temperature variation between climate scenarios showed the best correlation with species PGR variation along the latitudinal gradient, explaining $51 \%$ to $71 \%$ of PGR variation (see Table S4 for the overall seasonal correlations).

This article is protected by copyright. All rights reserved. 
By considering the mean temperature experienced in all the studied locations in the two climate scenarios, we identified specific patterns and non-linearity between responses at individual and population scales (Fig. 7). Individual and population responses appeared to be the same for $M$. gigas, with an overall increase with the warming scenario, whereas differences appeared for the mussel species. A decrease in individual growth rate (IGR) for was observed $M$. edulis beyond a break threshold close to $16^{\circ} \mathrm{C}$, while the threshold was at $14^{\circ} \mathrm{C}$ for the population growth rate (PGR). For M. galloprovincialis, the IGR increased in all locations whereas a break in PGR was simulated close to $16^{\circ} \mathrm{C}$ in a few locations.

\section{Biogeographic pattern of reproductive traits}

A decrease in the number of spawning events was simulated in locations south of $51^{\circ} \mathrm{N}$ for M. edulis and $M$. galloprovincialis in the case of the warming scenario, whereas a growing increase was simulated for M. gigas from south to north (Fig. 8a). Individual fecundity showed species-specific patterns along the latitudinal gradient (Fig. 8b): $M$. gigas had a mean increase of $+36 \pm 44 \%$, mostly shown at mid-latitudes, between 46 and $51^{\circ} \mathrm{N} ; M$. edulis showed a decrease in fecundity of $-13 \pm$ $14 \%$, mostly in northern locations up to $45^{\circ} \mathrm{N} ;$ M. galloprovincialis showed heterogeneous responses, with $+14 \pm 30 \%$ on average, and the highest increase at high-latitudes, beyond $48^{\circ} \mathrm{N}$.

When considering the spawning occurrence distribution across all locations studied, significant shifts of reproductive phenology were simulated for the three species (Fig. 9a). For M. gigas in the reference scenario, spawning events mostly occurred in July and September. With the warming scenario, the main spawning period was advanced by about one month, from the end of July to the end of June, with the second period reinforced and extended to the end of November. For M. edulis, spawning occurred all year long in the study area, with two main periods in the reference scenario, from April to June and from September to the end of November. Under the warming scenario, the first period was advanced and spawning events in late winter greatly reduced. For $M$. galloprovincialis in reference conditions, spawning periods were mostly in October-January with a second peak in May-July. Under the warming scenario, spring events were reduced and autumnal one reinforced.

Phenological shifts were spatially heterogeneous among the 150 locations studied (Fig. 9b). With the warming scenario, $M$. gigas spawning events appeared mostly delayed from July to August beyond $48^{\circ} \mathrm{N}$, whereas they were advanced from September to August south of $48^{\circ} \mathrm{N}$, compared with the reference scenario. M. edulis exhibited the most heterogeneous patterns, with a south to north gradient of the median spawning date simulated in the reference scenario, from April in the southern areas to October in the northern ones. Under the warming scenario, the spawning periods were homogenised towards spring events among the 150 locations. For M. galloprovincialis, spawning events were delayed overall and greater differences between scenarios were found at the edges of the study area, below $44^{\circ} \mathrm{N}$ and beyond $50^{\circ} \mathrm{N}$.

\section{DISCUSSION}

\section{Population response emerges from individual life-history traits}

We developed an individual-based population model and tested the sensitivity of the population growth potential of three bivalve species along $5000 \mathrm{~km}$ of coastline in the NE Atlantic according to a

This article is protected by copyright. All rights reserved. 
projected IPCC thermal stress scenario (RCP8.5) compared with reference levels, without local-scale density-dependent processes. As discussed by Kearney et al. (2010), with the perspective of combining mechanistic theoretical frameworks (i.e. biophysical ecology, geometric framework of nutrition and dynamic energy budget), this life-history trait-based modelling framework provides the opportunity for a better mechanistic understanding of species ecological niche. Spatial and temporal sensitivity of a population's dynamics emerged from our IBM approach (Schoener, 1986). This understanding of population dynamics patterns through individual physiological processes (i.e. feeding behaviour, thermal tolerance and reproductive traits) makes it possible to obtain detailed information on several biological traits, such as individual growth and fecundity, or population phenology and growth potential, from local to regional scales and with a high temporal frequency (i.e. daily). This approach fulfills the proposition of Woodin et al. (2013) to define biogeographic boundaries and species response to climate change by quantifying the significance of sub-lethal processes. Moreover, only a few of the current developments including population dynamics are focused on benthic species and of these only a few are spatially explicit and none aim to predict a response to global warming (e.g. Savina \& Ménesguen, 2008; Le Goff et al., 2017). When considered solely through a single level of biological organisation and/or organism-environment interaction, physiological and ecological performances may not scale directly (Huey \& Stevenson, 1979). Our IBM approach, combining the effects of several stressors at the individual level and evaluating the consequences at the population scale, is thus a powerful tool for testing scenarios and hypotheses.

However, even if modelling tools such as the DEB model are promising in this field for scenario building, it is still challenging to compare (and validate) simulations with observations at biogeographic scales, even more when studying life history traits such as phenology or fertility. Indeed, large-scale standardized datasets are scarce and there is a need for extended local observation networks in order to be able to test for the model parameters stationarity as demonstrated by Alunno-Bruscia et al. (2011). Direct comparison of our simulated growth and reproductive performances with observations is difficult mostly due to (1) possible discrepancies between local conditions and simulated ones and (2) inter-annual variability.

\section{Patterns of species response to warming}

The three bivalve species studied here show different patterns of thermal tolerance, in accordance with their physiological responses (e.g. growth, oxygen consumption and feeding) to varying temperature reported in the literature (van der Veer et al., 2006; Anestis et al., 2010; Fly \& Hilbish, 2013) (Fig. 3). These patterns led to significant differences in individual and population responses to the warming scenarios (Figs 4-7). M. gigas has the largest thermal tolerance range and appeared highly favoured by increased SST in every studied location. This species was introduced to European coasts in the 1960s and has extended its northern boundary from $47^{\circ} \mathrm{N}$ up to $60^{\circ} \mathrm{N}$ over recent decades as conditions became warmer (Troost, 2010). Increase of the $M$. gigas realized reproductive niche by seawater warming appeared as one of the main process explaining its biogeographic expansion (Diederich et al., 2005; Thomas et al., 2016). Considering the potential warming expected in the future (IPCC, 2014), our results show that the potential for M. gigas population development along European coasts could be greatly enhanced over coming decades if greenhouse gas emissions are not reduced. Even though its individual performances did not appear to be strongly increased in the warm scenario (i.e. individual growth increase under 15\%), a strong increase of its spawning frequency and individual fecundity sustained an increase in its reproductive efficiency and thus of its

This article is protected by copyright. All rights reserved. 
population growth rate potential. New areas suitable for the establishment of oyster populations even appeared in the north of the studied area, beyond $51^{\circ} \mathrm{N}$ (Fig. 8), which is in accordance with the current expansion tendency observed since the 2000s in northern areas such as the British Isles, northern Wadden Sea and Scandinavia (Wrange et al., 2009; Reise et al., 2017; Shelmerdine et al., 2017).

The mussel species studied showed more contrasting responses along the latitudinal gradient. $M$. edulis and $M$. galloprovincialis are known as cold- and warm-adapted species, respectively, and this difference manifested itself here through the offset of their thermal tolerance range, as shown in Fig. 3a. For M. edulis our simulation with RCP8.5 showed a PGR reduction in $40 \%$ of the studied locations at the end for the $21^{\text {st }}$ century, mostly those south of $50^{\circ} \mathrm{N}$, whereas $90 \%$ of locations showed enhanced PGR for M. galloprovincialis. The patterns of spawning triggering and bioenergetics linked to reproduction are key factors determining the response of populations of these species to warming, as our results demonstrated through the complex interactions apparent between the temperature threshold effect and fecundity level. From northern Spain to the eastern English Channel, three hybrid zones of these two mussel species currently occur: in the Bay of Biscay, western Brittany and Normandy, and geographical shifts of these hybrid zones have been already shown under climate warming (Hilbish et al., 2012). Our results reinforce the hypothesis of a potential modification of these hybrid zones under climate change forcing, due to the contraction of the southern distribution range of $M$. edulis and to the northern expansion of $M$. galloprovincialis under warming conditions (Fig. 6).

Although extreme temperatures need to be viewed as strongly determinant of species geographical ranges, particularly close to their range edges, we showed that in sub-lethal conditions, individual life-history traits controlled by metabolic performances are also significant drivers to take into account to understand the population dynamics response regarding climate change. We highlighted that PGR variations along the latitudinal gradient were strongly related to spring SST warming for the three species (Fig. 8), which is in accordance with previous studies in the same area (Hilbish et al., 2012; Fly et al., 2015; Thomas et al., 2016). Indeed, most of the growth and energy allocation to the reproduction occurs during spring, concomitantly with the phytoplankton bloom, rising temperature and the decrease in suspended inorganic particle concentration, due to lower turbulent mixing brought about by lowered wind conditions. We found a geographical heterogeneity in global seawater warming, consistent with previous studies in the NE Atlantic, which showed a north-south gradient along the coasts, explained by the poleward shelf and slope currents (Holt et al., 2010). Small-scale patterns of warming, showing for example a lower increase in SST in south Brittany, have also been described in previous studies comparing past and future SST scenarios under the "business as usual" (warming) scenario (Holt et al., 2010). From a biogeographic point of view, three areas with heterogeneous warming rates (i.e. temperature increase divided by the mean reference temperature, with temperatures express in ${ }^{\circ} \mathrm{C}$ ) may be identified: in the Bay of Biscay below $48^{\circ} \mathrm{N}$, with the lowest warming ( $+18 \%)$; along the English Channel between 48 and $51^{\circ} \mathrm{N}$, with a constant increase of warming rate (from $+18 \%$ to $+23 \%$ ); and in the Irish Sea beyond $51^{\circ} \mathrm{N}$, with the highest level of warming (+26\%) (Fig. 2). Although we used one of the best fitted and geographically realistic models for this area (L'Hévéder et al., 2017), we only applied a single realisation of future conditions. We also acknowledge that we were only able to assess the direction and magnitude of responses, but the probability of change still needs to be addressed (Constable, 1999). Thus, we cannot assign likelihood to the future simulation and our results should be seen as just one of the

This article is protected by copyright. All rights reserved. 
plausible projections. In addition, we used the most severe IPCC scenario with respect to global warming (RCP8.5). We can hope for a reduction in greenhouse gas emissions in the future in accordance with the Paris COP-21 agreement, which could limit SST warming. In that case, expected responses would be intermediate, between our Ref. and Proj. scenarios.

\section{Reproductive traits and phenology: key processes in population dynamics}

Our results in the reference scenario are consistent with observed life-history traits in the studied area, such as the fecundity. For $M$. edulis, the predicted mean number of oocytes per individual was of $15.5 \times 10^{6}$ (data not shown), corresponding to $6.9 \times 10^{6}$ oocytes $\mathrm{g}^{-1}$ dry weight, which is in the range of the review given by Sprung (1983) (i.e. 0.3 to $7.9 \times 10^{6}$ oocytes $\mathrm{g}^{-1}$ ). For M. galloprovincialis, the predicted mean number of oocytes per individual was of $23.4 \times 10^{6}$, in the range of observed fecundity of female mussels (e.g. $34 \times 10^{6}$ oocytes for $65 \mathrm{~mm}$ mussels; Schurink \& Griffiths, 1991). For M. gigas, the predicted mean fecundity was of $94.3 \times 10^{6}$ oocytes per individual, which is close to mean value observed in the studied area (e.g. $110 \times 10^{6}$ oocytes per individual for marketable oysters; Royer et al., 2008).

Our results are also consistent with observed geographic patterns of spawning periods, as exposed by Seed (1969): "Whilst generalizations are difficult, the extensive literature suggests that mussels from more southerly waters generally spawn prior to those from colder northern waters". Our simulations reproduced the same pattern in the reference scenario and showed that most of the spawning events occurred in early spring in southern locations (e.g. spawning in January-June in Arcachon Bay, Lubet, 1959). They also showed a shift in the timing of spawning toward northern locations where autumnal spawning events mainly occurred (e.g. September-October events in Cattewater, England, Bayne \& Worral, 1980). For M. galloprovincialis, information in the studied region is scarce. However, several spawning events have been reported in spring and autumn along Spanish coasts (see references in Cáceres-Martínez \& Figueras, 1998), in accordance with our simulations. For M. gigas, spawning mainly occurred in summer (July to September), which is in agreement with observed patterns (see e.g. Bernard et al., 2011).

Phenology, which defines the timing of life-history events such as spawning, settlement and migration, is a fundamental part of population dynamics for marine invertebrates. It dictates the match or mismatch of spawning time with optimal thermal and food conditions for early life stages, and with potential predators (Philippart et al., 2003). There is now evidence that species have experienced changes (e.g. advance, shift or contraction) in their phenology related to climate change (Parmesan \& Yohe, 2003; Poloczanska et al., 2013). Our simulations suggest, for the species studied, that rising temperatures should induce shifts in the timing of reproduction and concomitant modifications in spawning efficiency through the modification of individual fecundity (Fig. 9). Over the studied area, the spawning window, between $19^{\circ} \mathrm{C}$ and $30^{\circ} \mathrm{C}$, was extended for $M$. gigas under the warming scenario, whereas it was reduced in summer, between $10^{\circ} \mathrm{C}$ and $17^{\circ} \mathrm{C}$, for mussel species (Lubet, 1983). This contraction in the mussel spawning window profoundly modified the pattern of reproductive phenology. Seawater warming could thus promote synchronous spawning in spring for $M$. edulis. This could greatly change the reproductive cycle in the study area, which already showed a shift during recent decades: a single spawning event was observed in spring in the 1950 s to the 1980s, but both spring and autumn spawning have been observed since the 1990s,

This article is protected by copyright. All rights reserved. 
corresponding to our reference scenario (Philippart et al., 2012). Under seawater warming, we could expect the return to a single spawning period towards the spring months in $M$. edulis.

The coincidence of the larval stage with suitable environmental conditions (i.e. food and temperature) for growth and development is of primary importance for successful species recruitment (Philippart et al., 2014). Changes in species phenology expected under warming conditions, as revealed by the present simulations, might change these conditions. Larval development was not explicitly simulated in the present model, but, based on all the spawning events simulated, we explored the environmental conditions found immediately following each of these events and compared the reference and projected scenarios (Fig. S6). Food density increased in the majority of the locations (70\%) for M. gigas only, whereas PIM and temperature increased in the majority of the locations for all the species. Since the environmental conditions experienced by early life stages might change with sea warming, the consequences for population growth rate through recruitment success variation should be taken into account in the future to better predict larval supply.

\section{Scenario building}

Choosing appropriate physical and biological forcing variables at relevant spatial and temporal scales is a very challenging part of ecological process modelling. This task is particularly important when considering the effect of climate scenarios on species life-history traits (Kearney et al., 2012; Montalto et al., 2014). Such data need to be adapted to the species considered (e.g. benthic or pelagic) and to the issue addressed: from local short-term impacts (e.g. effect of habitat fractionation) to broad long-term ones (e.g. biogeography).

Seawater warming may have significant effects on phytoplankton communities (in terms of phenology, diversity and abundance) (Edwards \& Richardson, 2004; Beaugrand et al., 2009; Huertas et al., 2011; Hernández-Fariñas et al., 2014). We considered that interannual variation measured during our 15-year reference period along the $5000 \mathrm{~km}$ of coastline considered was adequate to reproduce the range of potential food variations. In addition, by applying a standard bias-correction method, we explored the expected effect of phytoplankton change under the warming scenario (Fig. S4). Even though spatial variations in trophic conditions appeared to be a strong driver of population growth potential (Fig. 5), our results show only a moderate effect of expected food density variation, with small PGR differences between reference and projected thermal conditions, applied with and without Chl-a projection (Fig. S5). Further developments in coupling biogeochemical and climate models are needed to overcome remaining uncertainties in climate models (Rickard et al., 2016). Indeed, there remains a need for further evaluation of species metabolism through primary production assessment. In such work, biogeochemical modelling approaches are valuable tools allowing environmental scenarios to be tested (Filgueira et al., 2016). In addition, other environmental variables modulate individual life-history traits and act on the population dynamics, such as the effects of air exposure, oxygen, salinity, acidification, spatial and trophic competition or predation. The methods provided in the present study constitute a basis for exploring the effects of these kinds of specific processes or stressors on benthic species population dynamics in a mechanistic and generic framework.

This article is protected by copyright. All rights reserved. 
Benthic coastal ecosystems, and a fortiori intertidal ones, are well known to be complex, with highly variable patterns and processes across spatial and temporal scales. Such patterns create an environmental mosaic leading to complex physiological responses (Helmuth, 2002; Helmuth et al., 2010). Beyond a better understanding of fine-scale patterns and processes, the improvement of climate model resolution through downscaling techniques should also enhance their application to predictions about living marine resources, especially in coastal ecosystems (Stock et al., 2011). In addition, our application, by using only one realisation of a single climate model, should evolve towards the use of an ensemble of climate models with several realisations based on different scenarios of greenhouse gas emissions, which would provide a more realistic prediction of expected temperatures (L'Hévéder et al., 2017).

\section{Main outcomes and prospects}

Our results strongly suggest that benthic species such as the Pacific oyster and blue mussel species will experience significant change in their population growth potential under the seawater warming conditions expected in the NE Atlantic if no slowing of greenhouse gas emissions is achieved. Food availability remains the main driver explaining spatial patterns at individual and population scales. However, changes of food availability will unlikely affect bivalve response as opposed to warming.

Seawater warming is already occurring, and shifts in reproductive phenology or population distribution range have already been reported in benthic species (Hilbish et al., 2012; Philippart et al., 2012). Even if adaptive processes interact with the expected response shown here, the projected rate of environmental change in coming decades would require a very rapid adaptation ability that could challenge the response capacity of benthic species. In any case, our findings reveal that expected warming would be great enough to produce a selective force linked to the thermal tolerance of the studied benthic species. This might have significant effects on benthic ecosystem functioning, partly through the modification of trophic relationships.

As shown by the non-linearity between species functional traits at the individual scale and their response at the population scale, patterns emerge from complex and sometime opposing responses in terms of biological organization. This highlights the need to integrate processes acting at both individual and population levels to properly understand the consequences of warming on benthic species. More realistic simulations will require integration of the processes regulating population density, by including spatial interactions (e.g. population connectivity and spatial competition) and mortality at all stages of the life cycle (e.g. ageing, starvation, predation). This is a key issue to be able to validate a functional trait-based modelling approach of this kind with long-term and broadscale in situ observations on demographic patterns.

\section{ACKNOWLEDGEMENTS}

This research was supported by a grant from Région Bretagne (SAD POPDEB ${ }^{\circ} 9277$ ) and Ifremer. Authors thank M. Vasquez (Ifremer, DYNECO) for putting together the EUSeaMap seabed habitat mapping information and C. Cassou (CNRS, Cerfacs) for putting together the climate model datasets.

This article is protected by copyright. All rights reserved. 


\section{REFERENCES}

Alunno-Bruscia M., Bourlès Y., Maurer D., Robert S., Mazurié J., Gangnery A., ... Pouvreau S. (2011). A single bio-energetics growth and reproduction model for the oyster Crassostrea gigas in six Atlantic ecosystems. Journal of Sea Research, 66(4), 340-348.

Anestis A., Pörtner H. O., Karagiannis D., Angelidis P., Staikou A. \& Michaelidis B. (2010). Response of Mytilus galloprovincialis (L.) to increasing seawater temperature and to marteliosis: Metabolic and physiological parameters. Comparative Biochemistry and Physiology Part A: Molecular \& Integrative Physiology, 156(1), 57-66. https://doi.org/10.1016/j.cbpa.2009.12.018.

Bayne B. L. \& Worral C. M. (1980). Growth and production of mussels Mytilus edulis from two populations. Marine Ecology Progress Series, 3, 317-328.

Beaugrand G., Luczak C. \& Edwards M. (2009). Rapid biogeographical plankton shifts in the North Atlantic Ocean. Global Change Biology, 15(7), 1790-1803. https://doi.org/10.1111/j.13652486.2009.01848.x.

Berg M. P., Kiers E. T., Driessen G., Van Der Heijden M., Kooi B. W., Kuenen F., ... Ellers J. (2010). Adapt or disperse: understanding species persistence in a changing world. Global Change Biology, 16(2), 587-598. https://doi.org/10.1111/j.1365-2486.2009.02014.x.

Bernard F. R. (1974). Annual biodeposition and gross energy budget of mature Pacific oysters, Crassostrea gigas. Journal of the Fisheries Research Board of Canada, 31(2), 185-190. https://doi.org/10.1139/f74-030.

Bernard I., de Kermoysan G. \& Pouvreau S. (2011). Effect of phytoplankton and temperature on the reproduction of the Pacific oyster Crassostrea gigas: Investigation through DEB theory. Journal of Sea Research, 66(4), 349-360.

Bougrier S., Geairon P., Deslous-Paoli J. M., Bacher C. \& Jonquières G. (1995). Allometric relationships and effects of temperature on clearance and oxygen consumption rates of Crassostrea gigas (Thunberg). Aquaculture, 134(1-2), 143-154. https://doi.org/10.1016/0044-8486(95)00036-2.

Buckley L. B., Urban M. C., Angilletta M. J., Crozier L. G., Rissler L. J. \& Sears M. W. (2010). Can mechanism inform species' distribution models? Ecology Letters, 13(8), 1041-1054. https://doi.org/10.1111/j.1461-0248.2010.01479.x.

Cáceres-Martínez J. \& Figueras A. (1998). Long-term survey on wild and cultured mussels (Mytilus galloprovincialis Lmk) reproductive cycles in the Ria de Vigo (NW Spain). Aquaculture, 162(1-2), 141-156. https://doi.org/10.1016/S0044-8486(98)00210-5.

Chavez-Villalba J., Pommier J., Andriamiseza J., Pouvreau S., Barret J., Cochard J.-C. \& Le Pennec M. (2002). Broodstock conditioning of the oyster Crassostrea gigas: origin and temperature effect. Aquaculture, 214(1-4), 115-130.

Constable A. J. (1999). Ecology of benthic macro-invertebrates in soft-sediment environments: A review of progress towards quantitative models and predictions. Australian Journal of Ecology, 24(4), 452-476. https://doi.org/10.1046/j.1442-9993.1999.00977.x.

Diederich S., Nehls G., van Beusekom J. E. E. \& Reise K. (2005). Introduced Pacific oysters

This article is protected by copyright. All rights reserved. 
(Crassostrea gigas) in the northern Wadden Sea: invasion accelerated by warm summers? Helgoland Marine Research, 59(2), 97-106.

Edwards M. \& Richardson A. J. (2004). Impact of climate change on marine pelagic phenology and trophic mismatch. Nature, 430(7002), 881-884. https://doi.org/10.1038/nature02808.

Fabioux C., Huvet A., Le Souchu P., Le Pennec M. \& Pouvreau S. (2005). Temperature and photoperiod drive Crassostrea gigas reproductive internal clock. Aquaculture, 250(1-2), 458-470.

Fearman J. \& Moltschaniwskyj N. A. (2010). Warmer temperatures reduce rates of gametogenesis in temperate mussels, Mytilus galloprovincialis. Aquaculture, 305(1-4), 20-25. https://doi.org/10.1016/j.aquaculture.2010.04.003.

Filgueira R., Guyondet T., Comeau L. A. \& Tremblay R. (2016). Bivalve aquaculture-environment interactions in the context of climate change. Global Change Biology, 22(12), 3901-3913. https://doi.org/10.1111/gcb.13346.

Fly E. K. \& Hilbish T. J. (2013). Physiological energetics and biogeographic range limits of three congeneric mussel species. Oecologia, 172(1), 35-46. https://doi.org/10.1007/s00442-0122486-6.

Fly E. K., Hilbish T. J., Wethey D. S. \& Rognstad R. L. (2015). Physiology and Biogeography: The Response of European Mussels (Mytilus spp.) to Climate Change. American Malacological Bulletin, 33(1), 136-149. https://doi.org/10.4003/006.033.0111.

Gangnery A., Bacher C. \& Buestel D. (2001). Assessing the production and the impact of cultivated oysters in the Thau lagoon (Mediterranee, France) with a population dynamics model. Canadian Journal of Fisheries and Aquatic Sciences, 58(5), 1012-1020. https://doi.org/10.1139/f01-028.

Gangnery A., Bacher C. \& Buestel D. (2004). Application of a population dynamics model to the Mediterranean mussel, Mytilus galloprovincialis, reared in Thau Lagoon (France). Aquaculture, 229(1-4), 289-313. https://doi.org/10.1016/S0044-8486(03)00360-0.

Gohin F. (2011). Annual cycles of chlorophyll-a, non-algal suspended particulate matter, and turbidity observed from space and in-situ in coastal waters. Ocean Science, 7, 705-732.

Grabowski J. H., Brumbaugh R. D., Conrad R. F., Keeler A. G., Opaluch J. J., Peterson C. H., ... Smyth A. R. (2012). Economic valuation of ecosystem services provided by oyster reefs. BioScience, 62(10), 900-909. https://doi.org/10.1525/bio.2012.62.10.10.

Guisan A. \& Zimmermann N. E. (2000). Predictive habitat distribution models in ecology. Ecological Modelling, 135(2-3), 147-186. https://doi.org/10.1016/S0304-3800(00)00354-9.

Harley C. D. G., Hughes A. R., Hultgren K. M., Miner B. G., Sorte C. J. B., Thornber C. S., ... Williams S. L. (2006). The impacts of climate change in coastal marine systems. Ecology Letters, 9, 228? $-241$.

Helmuth B. (2002). How do we measure the environment? Linking intertidal thermal physiology and ecology through biophysics. Integrative and Comparative Biology, 42(4), 837-845. https://doi.org/10.1093/icb/42.4.837.

This article is protected by copyright. All rights reserved. 
Helmuth B., Broitman B. R., Yamane L., Gilman S. E., Mach K., Mislan K. A. S. \& Denny M. W. (2010). Organismal climatology: analyzing environmental variability at scales relevant to physiological stress. Journal of Experimental Biology, 213(6), 995-1003. https://doi.org/10.1242/jeb.038463.

Helmuth B., Mieszkowska N., Moore P. \& Hawkins S. J. (2006). Living on the edge of two changing worlds: forecasting the responses of rocky intertidal ecosystems to climate change. Annual Review of Ecology, Evolution, and Systematics, 37, 373-404.

Hernández-Fariñas T., Soudant D., Barillé L., Belin C., Lefebvre A. \& Bacher C. (2014). Temporal changes in the phytoplankton community along the French coast of the eastern English Channel and the southern Bight of the North Sea. ICES Journal of Marine Science: Journal du Conseil, 71(4), 821-833.

Hilbish T. J., Lima F. P., Brannock P. M., Fly E. K., Rognstad R. L. \& Wethey D. S. (2012). Change and stasis in marine hybrid zones in response to climate warming. Journal of Biogeography, 39(4), 676-687. https://doi.org/10.1111/j.1365-2699.2011.02633.x.

Holt J., Wakelin S., Lowe J. \& Tinker J. (2010). The potential impacts of climate change on the hydrography of the northwest European continental shelf. Progress in Oceanography, 86(34), 361-379. https://doi.org/10.1016/j.pocean.2010.05.003.

Huertas I. E., Rouco M., López-Rodas V. \& Costas E. (2011). Warming will affect phytoplankton differently: evidence through a mechanistic approach. Proceedings of the Royal Society $B$ : Biological Sciences, 278(1724), 3534-3543. https://doi.org/10.1098/rspb.2011.0160.

Huey R. B. \& Stevenson R. D. (1979). Integrating Thermal Physiology and Ecology of Ectotherms: A Discussion of Approaches. American Zoologist, 19(1), 357-366.

IPCC (2014). IPCC, 2014: Climate Change 2014: Synthesis Report. Contribution of Working Groups I, II and III to the Fifth Assessment Report of the Intergovernmental Panel on Climate Change [Core Writing Team, R.K. Pachauri and L.A. Meyer (eds.)]. IPCC, Geneva, Switzerland.

Jolly M. T., Jollivet D., Gentil F., Thiebaut E. \& Viard F. (2004). Sharp genetic break between Atlantic and English Channel populations of the polychaete Pectinaria koreni, along the North coast of France. Heredity, 94(1), 23-32.

Kearney M. (2012). Metabolic theory, life history and the distribution of a terrestrial ectotherm. Functional Ecology, 26(1), 167-179. https://doi.org/10.1111/j.1365-2435.2011.01917.x.

Kearney M. R., Matzelle A. \& Helmuth B. (2012). Biomechanics meets the ecological niche: the importance of temporal data resolution. The Journal of Experimental Biology, 215, 922-933. https://doi.org/10.1242/jeb.059634.

Kearney M., Simpson S. J., Raubenheimer D. \& Helmuth B. (2010). Modelling the ecological niche from functional traits. Philosophical Transactions of the Royal Society B: Biological Sciences, 365(1557), 3469-3483.

Kearney M. \& Porter W. (2009). Mechanistic niche modelling: combining physiological and spatial data to predict species' ranges. Ecology Letters, 12(4), 334-350.

https://doi.org/10.1111/j.1461-0248.2008.01277.x.

This article is protected by copyright. All rights reserved. 
Kim Y. S. (1980). Efficiency of energy transfer by a population of the farmed pacific oyster, Crassostrea gigas in geoje-hansan bay. Bulletin of the Korean Fisheries Society, 13(4), 179193.

Kim Y. S. (1995). Filtering rate model of farming Oyster, Crassostrea gigas with effect of water temperature and size. Bulletin of the Korean Fisheries Society, 28(5), 589-598.

Kooijman S. A. L. M. (2006). Pseudo-faeces production in bivalves. Journal of Sea Research, 56, 103106.

Kooijman S. A. L. M. (2010). Dynamic Energy Budget Theory for Metabolic Organisation. Cambridge University Press, Cambridge, $490 \mathrm{pp}$.

Kusuky Y. (1977). On measurement of the filtration rates of the Japanese oyster. Bulletin of the Japanese Society of Scientific Fisheries, 43(9), 1069-1076.

Lannig G., Eilers S., Pörtner H. O., Sokolova I. M. \& Bock C. (2010). Impact of ocean Acidification on energy metabolism of oyster, Crassostrea gigas; changes in metabolic pathways and thermal response. Marine Drugs, 8(8). https://doi.org/10.3390/md8082318.

Le Gall P. \& Raillard O. (1988). Influence de la température sur la physiologie de l'huître Crassostrea. Océanis, 14(5), 603-608.

Le Goff C., Lavaud R., Cugier P., Jean F., Flye-Sainte-Marie J., Foucher E., ... Foveau A. (2017). A coupled biophysical model for the distribution of the great scallop Pecten maximus in the English Channel. Journal of Marine Systems, 167, 55-67. https://doi.org/10.1016/j.jmarsys.2016.10.013.

Le Moullac G., Quéau I., Le Souchu P., Pouvreau S., Moal J., René Le Coz J. \& François Samain J. (2007). Metabolic adjustments in the oyster Crassostrea gigas according to oxygen level and temperature. Marine Biology Research, 3(5), 357-366.

https://doi.org/10.1080/17451000701635128.

L'Hévéder B., Speich S., Ragueneau O., Gohin F. \& Bryère P. (2017). Observed and projected sea surface temperature seasonal changes in the Western English Channel from satellite data and CMIP5 multi-model ensemble. International Journal of Climatology, 37(6), 2831-2849. https://doi.org/10.1002/joc.4882.

Lubet P. (1959). Recherches sur le cycle sexuel et l'émission des gamètes chez les Mytilidés et les Pectinidés (Mollusques bivalves). Revue des Travaux de l'Institut des Pêches Maritimes, 23(4), 397-547.

Lubet P. E. (1983). Experimental studies on the action of temperature on the reproductive activity of the mussel (Mytilus edulis L., mollusca, lamellibranchia). Journal of Molluscan Studies, 49(supp12A), 100-105.

Mann R. (1979). Some biochemical and physiological aspects of growth and gametogenesis in Crassostrea gigas and Ostrea edulis grown at sustained elevated temperatures. Journal of the Marine Biological Association of the United Kingdom, 59, 95-110.

Mao Y., Zhou Y., Yang H. \& Wang R. (2006). Seasonal variation in metabolism of cultured Pacific oyster, Crassostrea gigas, in Sanggou Bay, China. Aquaculture, 253, 322-333.

This article is protected by copyright. All rights reserved. 
Martin B. T., Jager T., Nisbet R. M., Preuss T. G. \& Grimm V. (2013). Predicting Population Dynamics from the Properties of Individuals: A Cross-Level Test of Dynamic Energy Budget Theory. The American Naturalist, 181(4), 506-519. https://doi.org/10.1086/669904.

Mathewson P. D., Moyer-Horner L., Beever E. A., Briscoe N. J., Kearney M., Yahn J. M. \& Porter W. P. (2017). Mechanistic variables can enhance predictive models of endotherm distributions: the American pika under current, past, and future climates. Global Change Biology, 23(3), 1048-1064. https://doi.org/10.1111/gcb.13454.

Matzelle A. J., Sarà G., Montalto V., Zippay M., Trussell G. C. \& Helmuth B. (2015). A bioenergetics framework for integrating the effects of multiple stressors: opening a 'Black Box' in climate change research. American Malacological Bulletin, 33(1), 150-160. https://doi.org/10.4003/006.033.0107.

Montalto V., Sarà G., Ruti P. M., Dell'Aquila A. \& Helmuth B. (2014). Testing the effects of temporal data resolution on predictions of the effects of climate change on bivalves. Ecological Modelling, 278(0), 1-8. https://doi.org/10.1016/j.ecolmodel.2014.01.019.

Montalto V., Helmuth B., Ruti P. M., Dell'Aquila A., Rinaldi A. \& Sarà G. (2016). A mechanistic approach reveals non linear effects of climate warming on mussels throughout the Mediterranean sea. Climatic Change, 1-14. https://doi.org/10.1007/s10584-016-1780-4.

Nisbet R. M., McCauley E. \& Johnson L. R. (2010). Dynamic energy budget theory and population ecology: lessons from <em>Daphnia</em>. Philosophical Transactions of the Royal Society B: Biological Sciences, 365(1557), 3541. https://doi.org/10.1098/rstb.2010.0167.

Parmesan C. \& Yohe G. (2003). A globally coherent fingerprint of climate change impacts across natural systems. Nature, 421(6918), 37-42.

Pereira H. M., Leadley P. W., Proença V., Alkemade R., Scharlemann J. P. W., Fernandez-Manjarrés J. F., ... Walpole M. (2010). Scenarios for Global Biodiversity in the 21st Century. Science, 330(6010), 1496. https://doi.org/10.1126/science.1196624.

Pethybridge H., Roos D., Loizeau V., Pecquerie L. \& Bacher C. (2013). Responses of European anchovy vital rates and population growth to environmental fluctuations: An individualbased modeling approach. Ecological Modelling, 250(0), 370-383. https://doi.org/10.1016/j.ecolmodel.2012.11.017.

Philippart C. J. M., van Aken H. M., Beukema J. J., Bos O. G., Cadée G. C. \& Dekker R. (2003). Climaterelated changes in recruitment of the bivalve Macoma balthica. Limnology and Oceanography, 48(6), 2171-2185. https://doi.org/10.4319/lo.2003.48.6.2171.

Philippart C. J. M., van Bleijswijk J. D. L., Kromkamp J. C., Zuur A. F. \& Herman P. M. J. (2014). Reproductive phenology of coastal marine bivalves in a seasonal environment. Journal of Plankton Research, 36(6), 1512-1527. https://doi.org/10.1093/plankt/fbu073.

Philippart C. J. M., Amaral A., Asmus R., van Bleijswijk J., Bremner J., Buchholz F., ... Zuur A. F. (2012). Spatial synchronies in the seasonal occurrence of larvae of oysters (Crassostrea gigas) and mussels (Mytilus edulis/galloprovincialis) in European coastal waters. ECSA 46 Conference ProceedingsChanges and Challenges in Tidal and Estuarine Systems, 108, 52-63. https://doi.org/10.1016/j.ecss.2012.05.014.

Poloczanska E. S., Brown C. J., Sydeman W. J., Kiessling W., Schoeman D. S., Moore P. J., ...

This article is protected by copyright. All rights reserved. 
Richardson A. J. (2013). Global imprint of climate change on marine life. Nature Clim. Change, 3(10), 919-925.

R Development Core Team (2012). R: A language and environment for statistical computing. $R$ Foundation for Statistical Computing, Vienna, Austria. http://www.R-project.org/.

Reise K., Buschbaum C., Büttger H., Rick J. \& Wegner K. M. (2017). Invasion trajectory of Pacific oysters in the northern Wadden Sea. Marine Biology, 164(4), 68. https://doi.org/10.1007/s00227-017-3104-2.

Ren J. S., Ross A. H. \& Schiel D. R. (2000). Functional descriptions of feeding and energetics of the Pacific oyster Crassostrea gigas in New Zealand. Marine Ecology Progress Series, 208, 119130.

Rickard G. J., Behrens E. \& Chiswell S. M. (2016). CMIP5 earth system models with biogeochemistry: An assessment for the southwest Pacific Ocean. Journal of Geophysical Research: Oceans, 121(10), 7857-7879. https://doi.org/10.1002/2016JC011736.

Rinaldi A., Montalto V., Manganaro A., Mazzola A., Mirto S., Sanfilippo M. \& Sarà G. (2014). Predictive mechanistic bioenergetics to model habitat suitability of shellfish culture in coastal lakes. Estuarine, Coastal and Shelf Science, 144, 89-98. https://doi.org/10.1016/j.ecss.2014.04.013.

Royer J., Seguineau C., Park K.-I., Pouvreau S., Choi K.-S. \& Costil K. (2008). Gametogenetic cycle and reproductive effort assessed by two methods in 3 age classes of Pacific oysters, Crassostrea gigas, reared in Normandy. Aquaculture, 277, 313-320.

Rumrill S. S. (1990). Natural mortality of marine invertebrate larvae. Ophelia, 32(1-2), 163-198. https://doi.org/10.1080/00785236.1990.10422030.

Sarà G., Palmeri V., Rinaldi A., Montalto V. \& Helmuth B. (2013). Predicting biological invasions in marine habitats through eco-physiological mechanistic models: a case study with the bivalve Brachidontes pharaonis. Diversity and Distributions, 19(10), 1235-1247. https://doi.org/10.1111/ddi.12074.

Saraiva S., Van Der Meer J., Kooijman S. A. L. M., Witbaard R., Philippart C. J. M., Hippler D. \& Parker R. (2012). Validation of a Dynamic Energy Budget (DEB) model for the blue mussel Mytilus edulis. Marine Ecology Progress Series, 463, 141-158.

Saulquin B., Gohin F. \& Garrello R. (2011). Regional Objective Analysis for Merging High-Resolution MERIS, MODIS/Aqua, and SeaWiFS Chlorophyll-a Data From 1998 to 2008 on the European Atlantic Shelf. IEEE Transactions on Geoscience and Remote Sensing , 49(1), 143-154. https://doi.org/10.1109/TGRS.2010.2052813.

Savina M. \& Ménesguen A. (2008). A deterministic population dynamics model to study the distribution of a benthic bivalve with planktonic larvae (Paphia rhomboïdes) in the English Channel (NW Europe). Journal of Marine Systems, 70(1-2), 63-76. https://doi.org/10.1016/j.jmarsys.2007.03.001.

Scheffer M., Baveco J. M., DeAngelis D. L., Rose K. A. \& van Nes E. H. (1995). Super-individuals a simple solution for modelling large populations on an individual basis. Ecological Modelling, 80(2), 161-170. https://doi.org/10.1016/0304-3800(94)00055-M.

This article is protected by copyright. All rights reserved. 
Schoener T. W. (1986). Mechanistic Approaches to Community Ecology: A New Reductionism. American Zoologist, 26(1), 81-106.

Schurink C. van E. \& Griffiths C. L. (1991). A comparison of reproductive cycles and reproductive output in four southern African mussel species. Marine Ecology Progress Series, 76(2), 123134.

Seed R. (1969). The ecology of Mytilus edulis L. (Lamellibranchiata) on exposed rocky shores. Oecologia, 3(3), 277-316. https://doi.org/10.1007/BF00390380.

Shelmerdine R. L., Mouat B. \& Rachel J. S. (2017). The most northerly record of feral Pacific oyster Crassostrea gigas (Thunberg, 1793) in the British Isles. Biolnvasions Records, 6(1), 57-60. https://doi.org/doi.org/10.3391/bir.2017.6.1.09.

Shpigel M., Barber B. J. \& Mann R. (1992). Effects of elevated temperature on growth, gametogenis, physiology, and biochemical composition in diploid and triploid Pacific oysters: Crassostrea gigas Thunberg. Journal of Experimental Marine Biology and Ecology, 161, 15-25.

Somero G. N. (2012). The physiology of global change: Linking patterns to mechanisms. Annual Review of Marine Science, 4, 39-61. https://doi.org/10.1146/annurev-marine-120710100935.

Sousa T., Domingos T. \& Kooijman S. A. L. . (2008). From empirical patterns to theory: a formal metabolic theory of life. Philosophical Transactions of the Royal Society of London B: Biological Sciences, 363(1502), 2453-2464. https://doi.org/10.1098/rstb.2007.2230.

Sprung M. (1983). Reproduction and fecundity of the mussel $<i>$ Mytilus edulis $</ />$ at helgoland (North sea). Helgoländer Meeresuntersuchungen, 36(3), 243-255. https://doi.org/10.1007/BF01983629.

Stock C. A., Alexander M. A., Bond N. A., Brander K. M., Cheung W. W. L., Curchitser E. N., ... Werner F. E. (2011). On the use of IPCC-class models to assess the impact of climate on Living Marine Resources. Progress in Oceanography, 88(1), 1-27. https://doi.org/10.1016/j.pocean.2010.09.001.

Thomas Y., Pouvreau S., Alunno-Bruscia M., Barillé L., Gohin F., Bryère P. \& Gernez P. (2016). Global change and climate-driven invasion of the Pacific oyster (Crassostrea gigas) along European coasts: a bioenergetics modelling approach. Journal of Biogeography, 43(3), 568-579. https://doi.org/10.1111/jbi.12665.

Thompson R. J. (1984). Production, reproductive effort, reproductive value and reproductive cost in a population of the blue mussel Mytilus edulis from a subarctic environment. Marine Ecology Progress Series, 16(3), 249-257.

Thorson G. (1950). Reproductive and larval ecology of marine bottom invertebrates. Biological Reviews, 25(1), 1-45. https://doi.org/10.1111/j.1469-185X.1950.tb00585.x.

Tracy C. R. \& Christian K. A. (1986). Ecological Relations Among Space, Time, and Thermal Niche Axes. Ecology, 67(3), 609-615. https://doi.org/10.2307/1937684.

Troost K. (2010). Causes and effects of a highly successful marine invasion: Case-study of the introduced Pacific oyster Crassostrea gigas in continental NW European estuaries. Journal of Sea Research, 64(3), 145-165.

This article is protected by copyright. All rights reserved. 
van der Veer H. W., Cardoso J. F. M. F. \& van der Meer J. (2006). The estimation of DEB parameters for various Northeast Atlantic bivalve species. Dynamic Energy Budgets in Bivalves, 56(2), 107-124. https://doi.org/10.1016/j.seares.2006.03.005.

van Vuuren D. P., Edmonds J., Kainuma M., Riahi K., Thomson A., Hibbard K., ... Rose S. K. (2011). The representative concentration pathways: an overview. Climatic Change, 109(1), 5. https://doi.org/10.1007/s10584-011-0148-z.

Wethey D. S., Woodin S. A., Hilbish T. J., Jones S. J., Lima F. P. \& Brannock P. M. (2011). Response of intertidal populations to climate: Effects of extreme events versus long term change. Global change in marine ecosystems, 400(1-2), 132-144. https://doi.org/10.1016/j.jembe.2011.02.008.

Woodin S. A., Hilbish T. J., Helmuth B., Jones S. J. \& Wethey D. S. (2013). Climate change, species distribution models, and physiological performance metrics: predicting when biogeographic models are likely to fail. Ecology and Evolution, 3(10), 3334-3346.

https://doi.org/10.1002/ece3.680.

Wrange A. L., Valero J., Harkestad L. S., Strand $\varnothing$., Lindegarth S., Christensen H. T., ... Mortensen S. (2009). Massive settlements of the Pacific oyster, Crassostrea gigas, in Scandinavia. Biological Invasions, 12(6), 1453-1458.

Yasuoka N. \& Yusa Y. (2016). Effects of size and gregariousness on individual sex in a natural population of the Pacific oyster Crassostrea gigas. Journal of Molluscan Studies, 82(4), 485491. https://doi.org/10.1093/mollus/eyw020.

Yusa Y., Breton S. \& Hoeh W. R. (2013). Population Genetics of Sex Determination in Mytilus Mussels: Reanalyses and a Model. Journal of Heredity, 104(3), 380-385. https://doi.org/10.1093/jhered/est014.

\section{Supporting information}

File 1/1: Additional tables and figures referred in the main text.

This article is protected by copyright. All rights reserved. 


\section{Figure captions}

Fig. 1. Time series of the forcing variables in contrasting locations. Daily profiles of (a) chlorophyll-a (Chl-a) concentration, (b) particulate inorganic matter (PIM) concentration derived from satellite data and $(\mathbf{c}-\mathbf{d})$ reference and projection of sea surface temperature (SST). The selected locations (S1 in the south and S2 in the north) are indicated in Fig 2.

Fig. 2. Maps of the forcing variables. Each point corresponds to one of the 150 locations. In panels (a-c) the point colours give the level of yearly mean for each variable, Chl-a, PIM and SST derived from satellite data, respectively. The point size is proportional to the coefficient of variation (CV, \%; see legend on each panel). Panel (d) gives the mean SST warming per decade between the two climate scenarios. Arrows indicate two selected points (S1 in the south and S2 in the north), for which the time series are given in Fig 1.

Fig. 3. Species metabolic response to temperature: (a) Species temperature correction factor $\left(T_{C}\right)$ computed according to the Arrhenius function and applied to the metabolic rates in the DEB model, in the $0-35^{\circ} \mathrm{C}$ range (see methods) and (b) probability distribution functions of the daily $T_{C}$ according to the two climate scenarios simulated for all locations: Ref. (2000-2015) and Proj. (20852100 ), for the three species ( $n=8.2 \times 10^{5}$ for each scenario). Scenario averages are indicated by solid vertical lines and barred symbols, and the species-specific maximum $T_{\text {cmax }}$ is indicated by a dashed line.

Fig. 4. Map of the individual yearly growth response to the warming scenario (RCP8.5). Results are expressed as the percentage difference in final physical length $(L w)$ after one year of simulation between the projected (Proj.) and reference (Ref.) scenarios: $100 \times$ (Proj.-Ref.)/Ref.. Results are averaged over the 15-year periods. Species names are given at the top of each panel. The same colour-ramp is used for the three species.

Fig. 5. Species population growth rate (PGR) as a function of mean temperature and individual functional response (i.e. food effect). Symbol and line colour are scaled and represent the population growth rate (PGR) value. Symbol shape distinguishes the three scenarios: "Ref.", "Proj." and "food".

Fig. 6. Maps of the species population growth rate (PGR) variation under the warming scenario (RCP8.5). Results are expressed as the percentage of variation in PGR between the projected (Proj.) and reference (Ref.) scenario: $100 \times$ (Proj. - Ref.)/Ref.. Species names are given at the top of each panel. The same colour ramp is used for mussel species and a different colour-ramp is used for the oyster, with log-transformed data.

Fig. 7. Individual (IGR) and population (PGR) growth rate as a function of temperature. Each pair of points connected by a grey line represents one location. Point shapes and colours identify reference and projection scenarios. Standardized values are deviations from the location averages.

Fig. 8. Simulated reproductive response to climate scenarios and biogeographic significance. Difference in (a) the number of spawning events (log-scale for M. gigas) and (b) fecundity (i.e. mean egg number per spawning event per individual) along the latitudinal gradient for the three species between the climate scenarios (each point represents one location). Data are expressed as a percentage of variation: $100 \times$ (Proj.-Ref.)/Ref.. The lines correspond to the local polynomial regression fitted for each species, and the coloured surface represent the standard error of each regression.

This article is protected by copyright. All rights reserved. 
Fig. 9. Simulated reproductive phenology depending on climate scenarios and biogeographic significance. (a) Occurrence distribution function of the spawning dates simulated for each species according to the climate scenarios. Data are expressed as the scaled (standard score-z) number of spawning events for all locations and cohorts combined. (b) Median spawning date in every location (points) for all cohorts combined and corresponding 25\% and $75 \%$ quartiles (extremities of the lines on left- and right-side of the points, respectively).

This article is protected by copyright. All rights reserved. 
(a)

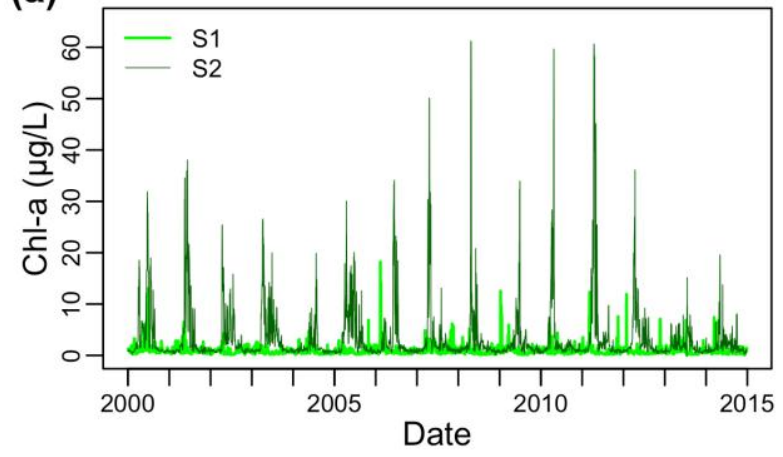

(c)

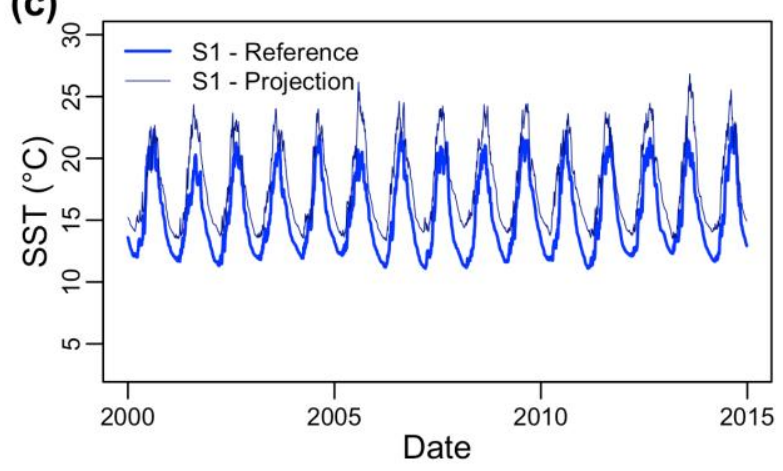

(b)

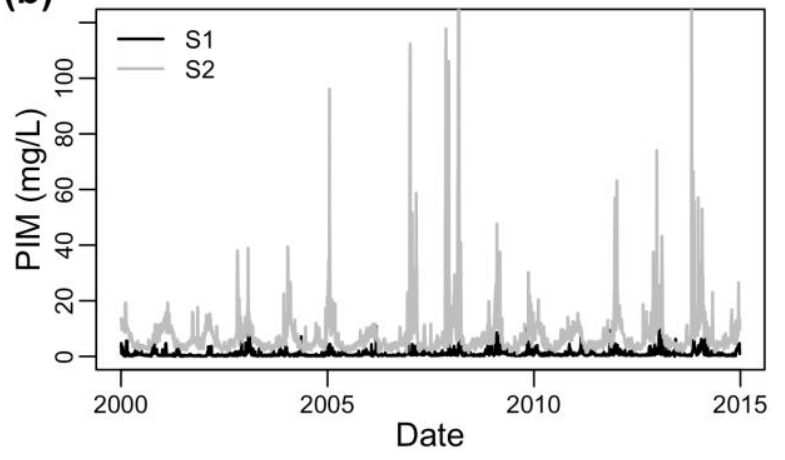

(d)

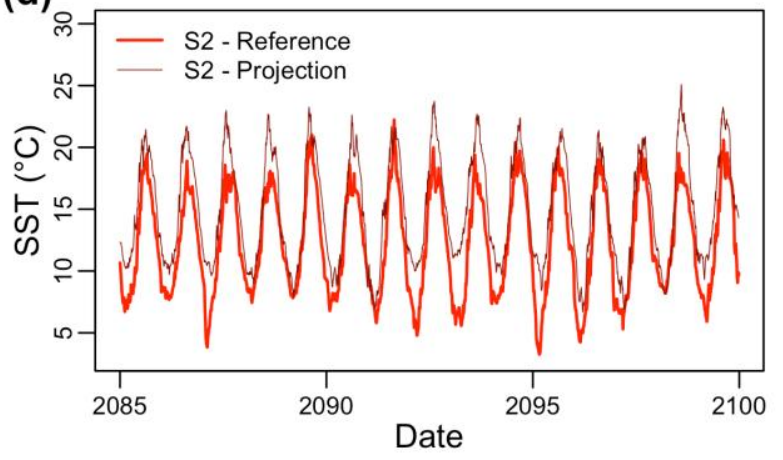

This article is protected by copyright. All rights reserved. 
(a)

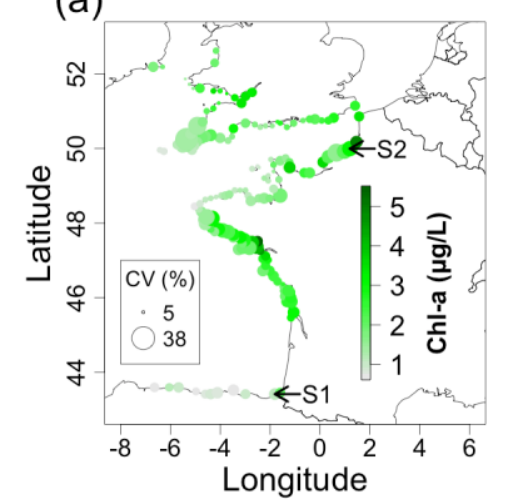

(c)

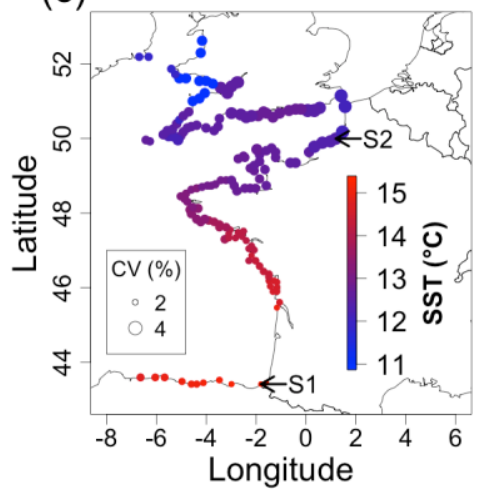

(b)



(d)

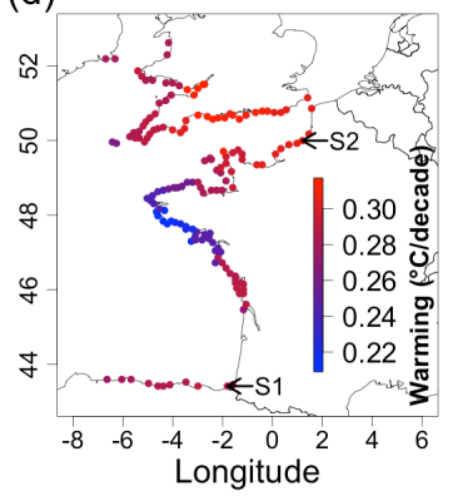

This article is protected by copyright. All rights reserved. 
(a)

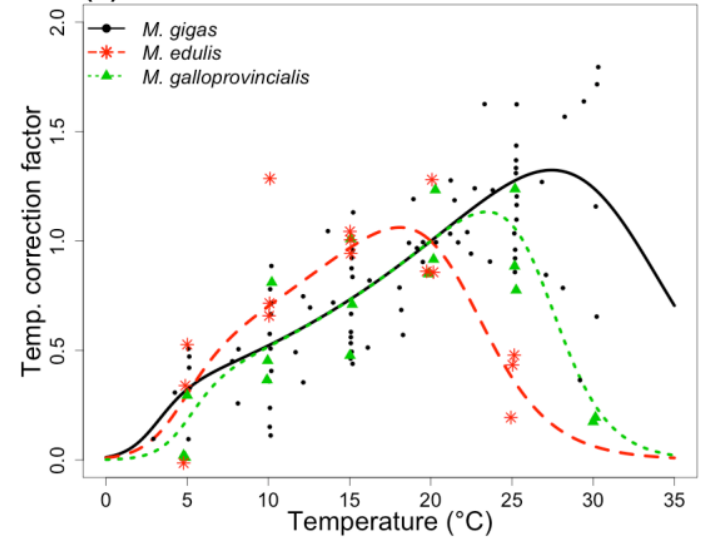

(b)

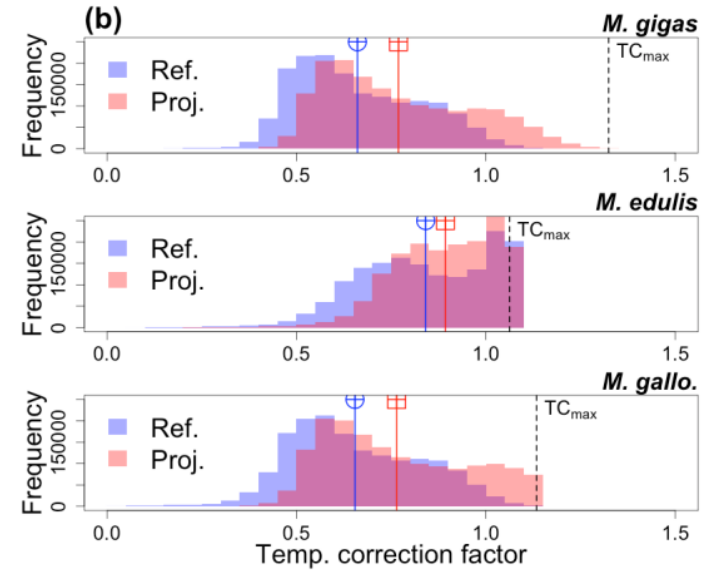

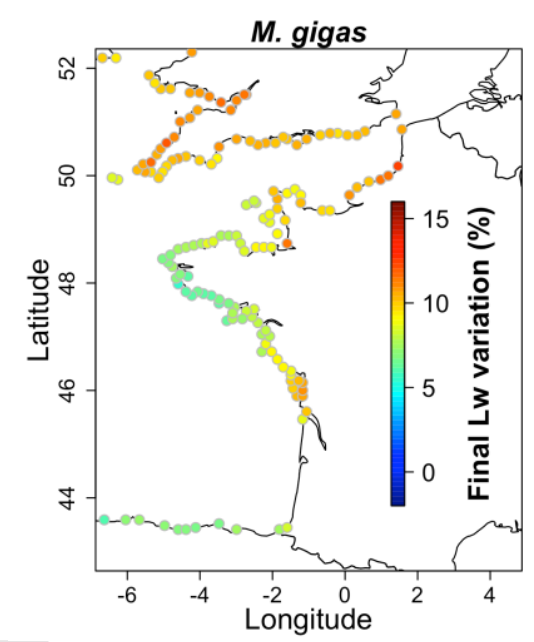
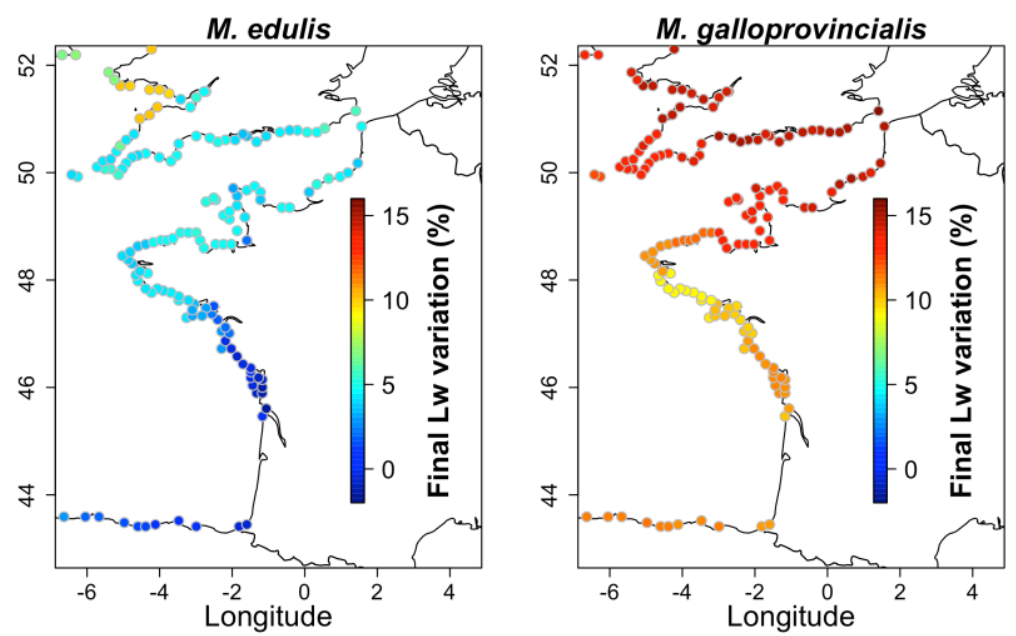

This article is protected by copyright. All rights reserved. 

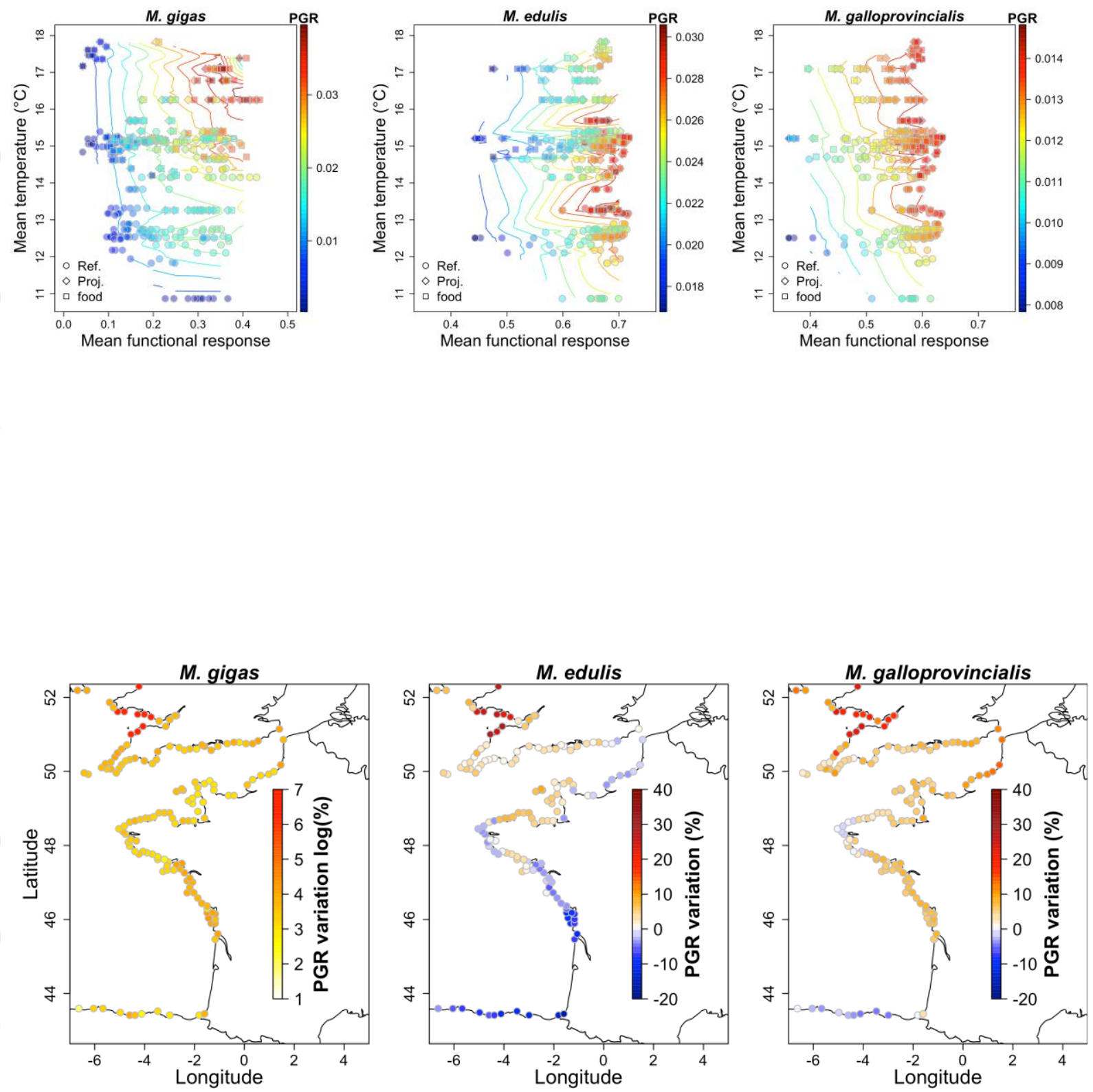

This article is protected by copyright. All rights reserved. 

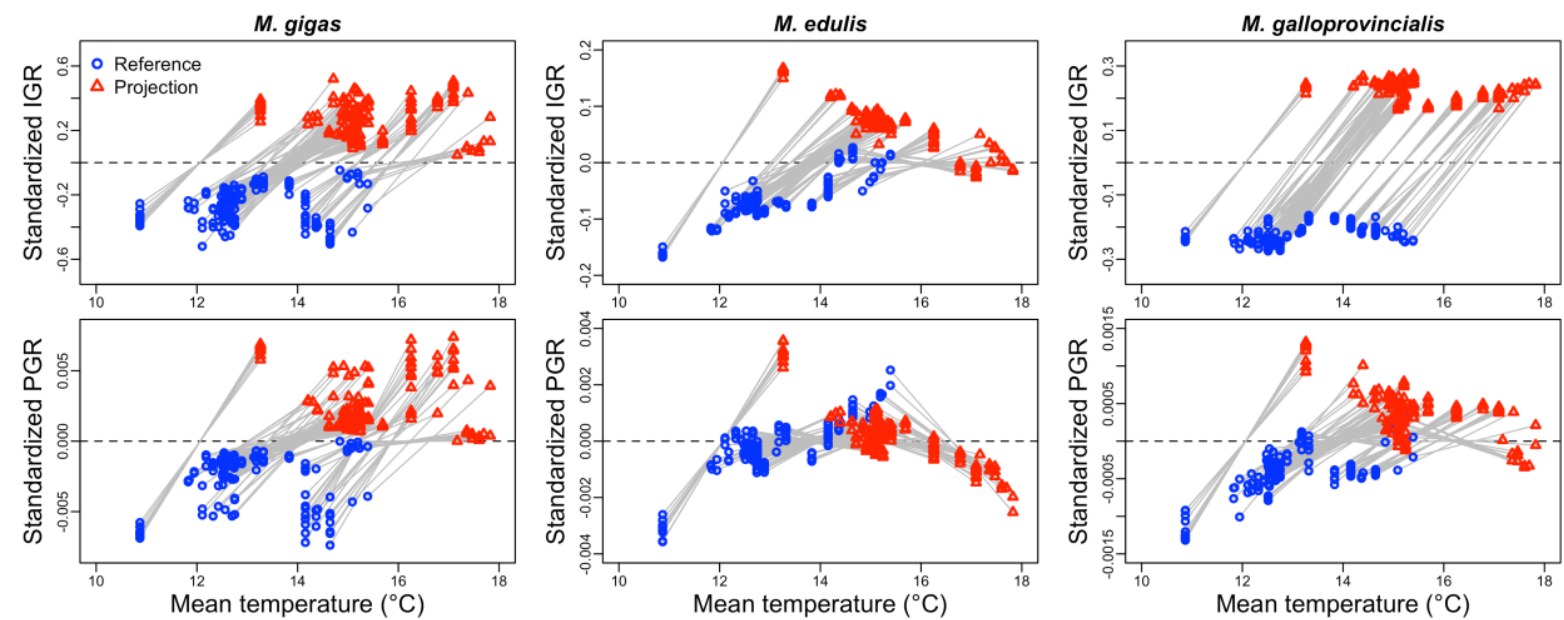

This article is protected by copyright. All rights reserved. 
(a)

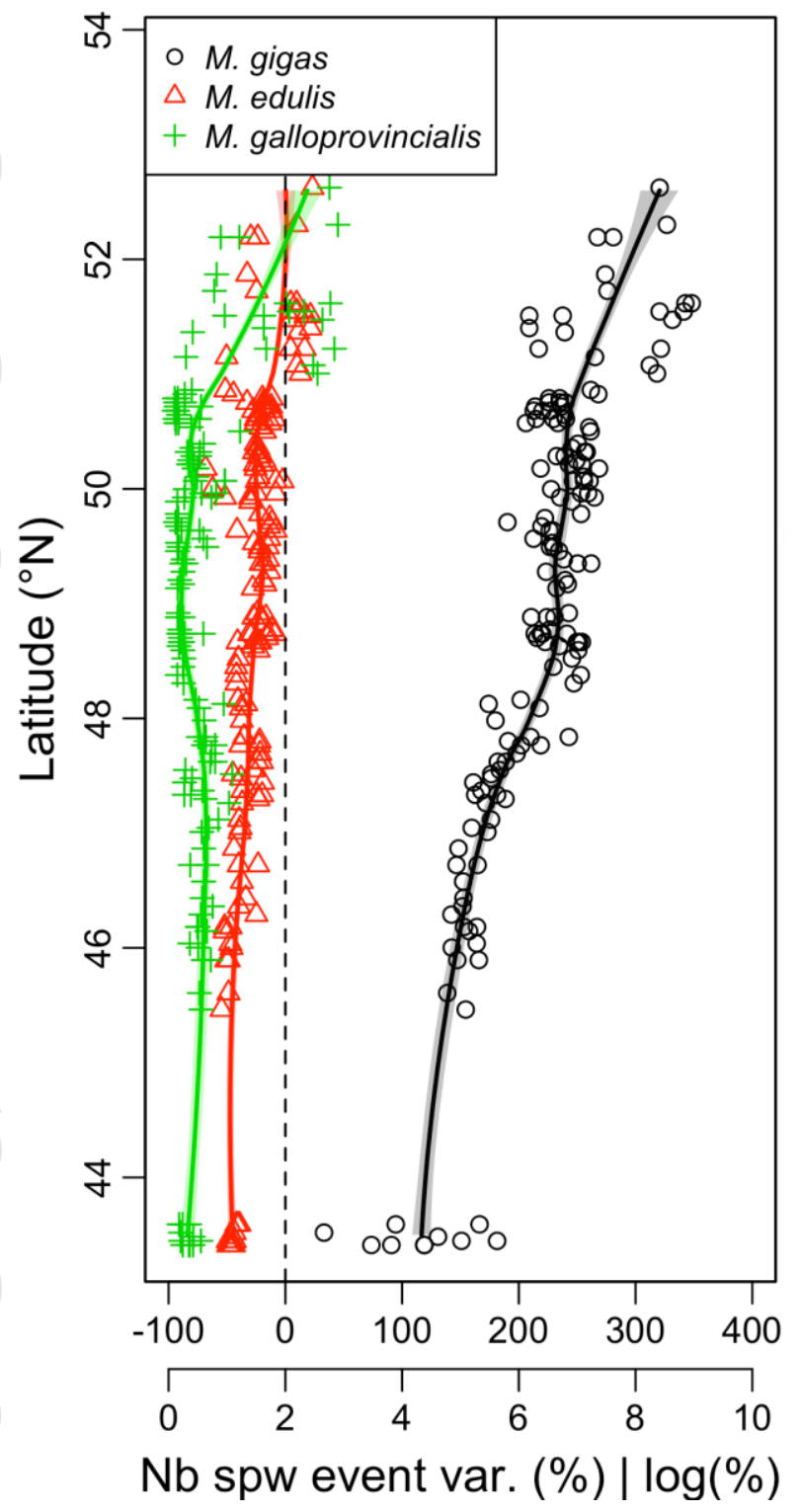

(b)



This article is protected by copyright. All rights reserved. 

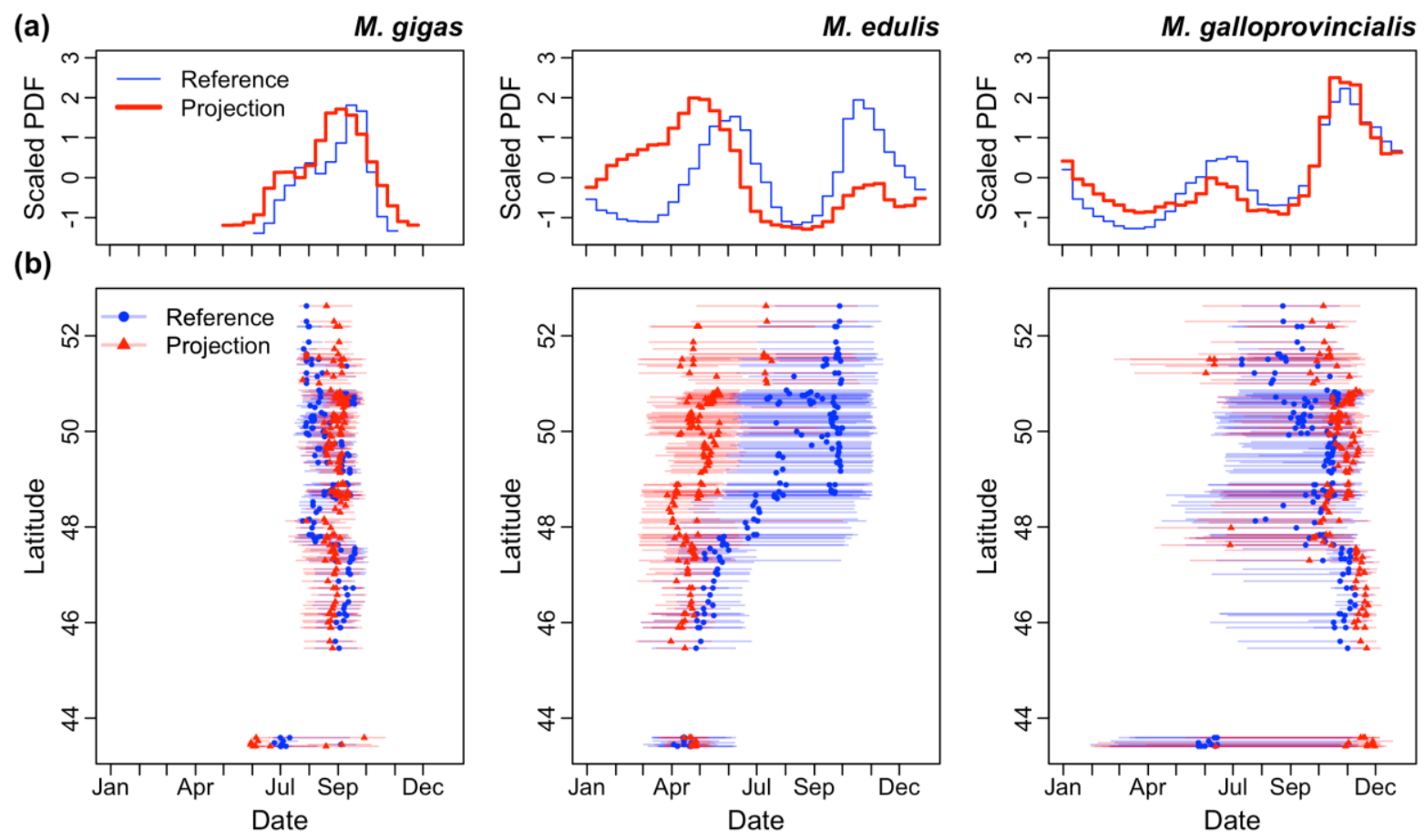

This article is protected by copyright. All rights reserved. 